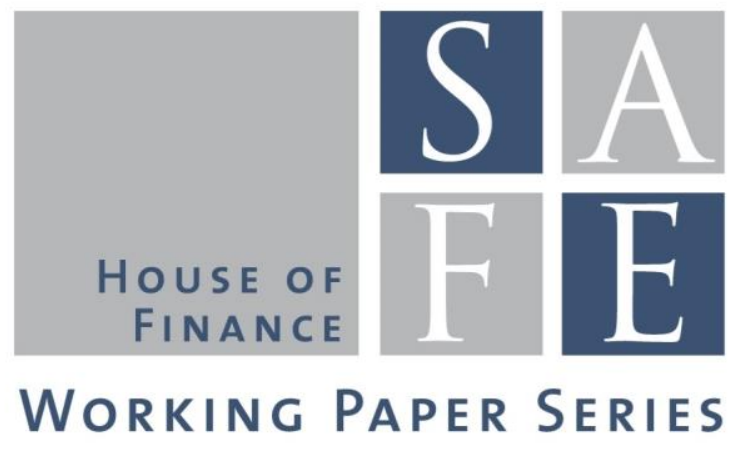

Christian Geppert - Alexander Ludwig - Raphael Abiry

\title{
Secular Stagnation? Growth, Asset Returns and Welfare in the Next Decades: First Results
}

SAFE Working Paper No. 145

SAFE I Sustainable Architecture for Finance in Europe A cooperation of the Center for Financial Studies and Goethe University Frankfurt 


\section{Non-Technical Summary}

The present paper analyzes the role of demographic change for "secular stagnation" - a longrun or trend reduction of growth that can be caused by too little investments compared to the amount of savings. But what are the effects of aging societies for secular stagnation in the next decades?

First, we ask if-and if so, how strongly and for how long-demographic change will effect growth of the US economy in the next decades. Second, we investigate whether the potential reduction of growth is accompanied by a decline of real rates of return. Third, in terms of policy implications, we emphasize that human capital policies may play an important role in the next decades.

Demographic changes will lead to a relative scarcity of raw labor to the effect that output growth will be decreasing. As capital will be relatively abundant, this decrease of output will be accompanied by reductions of asset returns. We quantify these effects for the US economy by developing an overlapping generations model with risky and risk-free assets.

We show that cumulative output losses from reductions of raw labor may stand at minus $6 \%$ in 2035, relative to a constant growth path. Endogenous human capital adjustments may strongly reduce these losses to about minus $2 \%$. This relative reduction in long-run output will be accompanied by falling asset returns. Risky returns are projected to decrease by 0.7 , respectively 0.16 , percentage points and risk-free returns by 1.0 , respectively 0.24 , percentage points without, respectively with, human capital adjustments.

Since we find that endogenous human capital adjustments will strongly mitigate the adverse effects of demographic change on output growth, capital returns and welfare, we conclude that human capital policies will be crucial in this context. 


\title{
Secular Stagnation? Growth, Asset Returns and Welfare in the Next Decades: First Results*
}

\author{
Christian Geppert ${ }^{\dagger} \quad$ Alexander Ludwig ${ }^{\ddagger} \quad$ Raphael Abiry ${ }^{\ddagger}$
}

September 8, 2016

\begin{abstract}
Ongoing demographic change will lead to a relative scarcity of raw labor to the effect that output growth will be decreasing in the next decades, a secular stagnation. As physical capital will be relatively abundant, this decrease of output will be accompanied by reductions of asset returns. We quantify these effects for the US economy by developing an overlapping generations model with risky and risk-free assets. Without adjustments of human capital, risky returns decrease until 2035 by about 0.7 percentage point, and the risk-free rate by about one percentage point, leading to substantial welfare losses for asset rich households. Per capita output is reduced by $6 \%$. Endogenous human capital adjustments strongly mitigate these effects. We conclude that human capital policies will be crucial in the context of labor shortages.
\end{abstract}

JEL classification: E17, C68, G12

Keywords: secular stagnation; demographic change; overlapping generations; natural rate; equity premium; growth; welfare; human capital

*We thank Martin Barbie, Axel Börsch-Supan, Helge Braun, Wouter den Haan, Daniel Harenberg, Philip Jung, Tom Krebs, Wolfgang Kuhle, and Edgar Vogel for helpful discussions and seminar/conference participants at various places for valuable comments. We also gratefully acknowledge financial support by the German National Research Foundation (SPP 1578) and by the Research Center SAFE, funded by the State of Hessen initiative for research LOEWE. The usual disclaimer applies. In particular, the views expressed in this paper do not represent the official positions of the OECD or the governments of the OECD member countries.

$\dagger$ Directorate for Employment, Labour and Social Affairs, Organisation for Economic Development and Co-operation, Paris

${ }^{\ddagger}$ SAFE, Goethe University Frankfurt. 


\section{Introduction}

In his famous keynote addresses at the IMF in 2013 and at the NABE Policy conference in 2014, Summers $(2013,2014)$ argued in terms of three propositions as follows: in consequence of "secular stagnation" - a long-run or trend reduction of growth $^{1}$ - (i) it will be "increasingly difficult" to achieve "adequate growth" in the US and other industrialized economies; (ii) that these developments will likely be accompanied by "a substantial decline in the equilibrium or natural rate of interest"; and (iii) that "addressing these challenges requires different policy approaches than are represented by the current conventional wisdom". ${ }^{2}$

The present paper analyzes the role of demographic change for a secular stagnation along all three propositions. First, we ask if - and if so how strongly and for how long - demographic change will effect growth of the US economy in the next decades. We do so by developing a structural model of an economy with a production sector and a household sector in order to capture how the relative demands and supplies of production factors change in consequence of the demographic evolution over the next decades. In order to realistically capture these demographic developments, we develop an overlapping generations model featuring a very detailed description of the aging process ${ }^{3}$ and its role for household decisions.

Second, we investigate whether the potential reduction of growth is accompanied by a decline of real rates of return. To do so we explicitly distinguish between equilibrium risky asset returns and the returns of a (one period ahead) risk-free bond. While standard predictions suggest that demographic change leads to a shortage of labor and an abundance of physical capital to the effect that marginal productivities and hence asset returns decline, these effects may be very different across asset classes. Older households may have a higher preference for relatively riskfree investments which would increase relative demand for bonds. Therefore, bond returns may decrease by more than risky asset returns. Also, our distinction between different assets enables us to be explicit about the notion of the "natural

\footnotetext{
${ }^{1}$ The term secular is used in contrast to cyclical or short-term, and suggests a change of fundamental dynamics. The term was originally coined by Hansen (1938).

${ }^{2}$ See Summers (2014, p. 66). As Summers (2014) further points out, one reason for secular stagnation might be the demographic development over the next decades leading to an increasing shortage of labor thereby depressing output.

${ }^{3}$ We use the terms "demographic change" and "aging" interchangeably.
} 
rate" which provides important guidance for central banks for their interest rate policies. According to Wicksell (1898), the natural rate of interest is the interest rate which is compatible with a stable price level. In monetary theory the workhorse model of central bank behavior is the Tayor rule (Taylor 1993) which models the nominal interest rate as the natural rate plus some deviation terms. Hence, an appropriate model of the development of the natural rate is required for fine tuning monetary policy instruments. We deliver such a forecasting instrument by modeling the supply side of assets through a production sector with a capital structure with exogenous leverage, i.e., we assume that an exogenous share of total firms' assets is held in equity, the rest in bonds. ${ }^{4}$ The demand side for differential assets stems from the household sector where intra-generational heterogeneity - induced by stochastic income processes - and intergenerational heterogeneity (by age) gives rise to trade across households in both assets.

Third, in terms of policy implications, we emphasize that human capital policies may play an important role in the next decades. While we do not model these policies explicitly, we consider two polar human capital scenarios. In our first scenario we restrict human capital adjustments. Then, accumulated losses in per capita output until year 2035 - resulting from the demography induced reduction of growth ratesstand at roughly 6 percent relative to a constant growth environment. Risky asset returns decrease by 0.7 and bond returns by 1 percentage point until 2035. These relatively strong effects would lead to quite strong welfare losses for middle aged and old households who hold substantial physical and financial wealth. In our second scenario households react to increasing life-expectancy and increasing wages as well as falling real asset returns by increasing their human capital investments. Then per capita output decreases by only 2 percent (relative to a long-run path with constant growth rates). Risky asset returns decrease by roughly 0.16 and risk-free returns by 0.24 percentage points. These quantitative effects are rather mild. In light of real world frictions on markets for human capital (which we do not model) ${ }^{5}$ we argue that our two scenarios bracket the evolution of future asset returns, growth and welfare.

\footnotetext{
${ }^{4}$ Leverage is frequently modeled this way in the finance literature to increase the volatility of stock returns, cf., e.g., Boldrin, Christiano, and Fisher (1995) and Croce (2014).

${ }^{5}$ Such elements are not included in the model for technical reasons. As further discussed below, we achieve computational tractability by using a specific framework giving rise to closed form solutions of households' policy functions. These analytical results would seize to exist in a setup with frictions.
} 
Furthermore, we show that social security policies that hold constant contribution rates may be welfare improving. ${ }^{6}$ Only then the aforementioned dampening effects on aggregate results and on welfare through human capital adjustments are at work.

These results are driven by demographic developments which we take as exogenous. According to our demographic projections, the working age population ratio ${ }^{7}$ will decrease by roughly 10 percentage points. The ensuing shortage of the quantity of raw labor and the accompanying relative abundance of physical capital leads to decreasing output, increasing gross wages and falling asset returns. These relative price movements - in combination with the increasing life-time horizon resulting from increasing life expectancies — will lead households to increase their human capital investments because relative human capital returns increase. As a result of human capital adjustments, the reductions of output and of capital productivity as well as equilibrium asset returns will be mitigated. Furthermore, our model predicts that average portfolio shares of investments in risky assets are decreasing over the life-cycle. Because demographic change shifts population shares so that there are relatively more elderly households - the old-age dependency ratio ${ }^{8}$ increases by more than 15 percentage points - the demand for bonds relative to equities increases. This reduces bond returns more strongly, hence the equity premium increases.

We contribute to a growing literature on secular stagnation. A collection of overview articles on the topic is given in Teulings and Baldwin (2014). Eggertsson and Mehrotra (2014) develop a New Keynesian model with overlapping generations in which a deleveraging shock leads to an oversupply of savings triggering low interest rates. In their framework, the same effects would be caused by a drop of the population growth rate. Eggertsson, Mehrotra, and Summers (2016) employ a two-country model to study how capital flows transmit shocks in a low interest rate environment. Relative to this literature, we emphasize demographics as the key source of the joint phenomenon of low growth and low interest rates. For simplicity, we look at a closed economy model. ${ }^{9}$ Similar to our contribution, Carvalho, Fer-

\footnotetext{
${ }^{6}$ These results are not yet contained in the current version of the paper.

${ }^{7}$ I.e., the fraction of the population in working age (age 20-64) relative to the total adult population.

${ }^{8}$ I.e., the population in retirement age (age 65 and older) as a fraction of the working age population.

${ }^{9}$ This is a fair approximation for the US economy. E.g., in a purely deterministic multi-country overlapping generations model with international capital flows driven by heterogenous demographic developments, Krüger and Ludwig (2007) show that world interest rates faced by the US alter
} 
rero, and Nechio (2016) investigate whether demographic developments drive down real interest rates. They focus on a deterministic environment with one asset and accordingly cannot study differential asset returns as we do.

Our work also relates to a relatively large literature that employs variants of Auerbach and Kotlikoff (1987) overlapping generations models to quantitatively evaluate the consequences of demographic change for growth and welfare, cf., e.g., BörschSupan, Ludwig, and Winter (2006), Attanasio, Kitao, and Violante (2007), Krüger and Ludwig (2007), Ludwig, Schelkle, and Vogel (2012) and the literature cited therein. Relative to this literature, the main novel aspect in our work is to explicitly model differential asset returns. We thereby relate to a literature on aging and the equity premium (Bakshi and Chen 1994; Brooks 2004; Börsch-Supan, Ludwig, and Sommer 2003; Geanakoplos, Magill, and Quinzii 2004; Kuhle 2008) which has not reached a consensus on the quantitative effects of demographic change on differential asset returns. While Brooks (2004) reports substantial increases in the equity premium, the approximate calculations in Börsch-Supan, Ludwig, and Sommer (2003) rather suggest a small increase. Geanakoplos, Magill, and Quinzii (2004) conclude that "the equity premium is smaller when the population of savers is older" which the authors interpret as a contradiction to the findings of Bakshi and Chen (1994) and Brooks (2004). These papers all employ relatively stylized overlapping generations models with few generations. Such a periodicity severely restricts households to re-balance their portfolios. We avoid such restrictions by employing a large scale overlapping generations model that runs at an annual frequency. To significantly reduce computational costs we adopt the risky human capital framework developed in Krebs (2003) and Krebs and Wilson (2004). This setup gives rise to closed form solutions of households' policy functions for consumption and total saving, conditional on the law of motion of the aggregate state of the economy and the solution for optimal portfolio shares. ${ }^{10}$

This paper proceeds as follows. Section 2 develops the large scale quantitative overlapping generations model. Section 3 describes our approach to numerically solve this model as well as the model's calibration. Section 4 presents the results relatively little between closed and open economy variants of their model.

${ }^{10}$ Human capital is modeled as an asset and in suitable transformation of our model reduces to a standard portfolio choice model. Once portfolio shares are computed, policy functions of savings and consumption are linear in wealth, as in the seminal work by Merton (1969) and Samuelson (1969). 
and, finally, Section 5 concludes. Separate appendices provide proofs of propositions and additional results.

\section{Quantitative Model}

We extend the classical Diamond (1965) economy to a multi-period setup as in Auerbach and Kotlikoff (1987) with idiosyncratic and aggregate risk. On the household side, labor income is a choice variable which we implement by adopting the human capital framework developed in Krebs (2003) and Krebs and Wilson (2004) in an overlapping generations setup. In each period, a household of a given age chooses to invest a fraction of her overall wealth in human capital, respectively financial capital. As for the fraction of wealth invested in financial assets, the household solves a standard portfolio allocation problem by choosing how much to invest into risky physical capital and (one period ahead) risk-free bonds. Consequently, there are three assets in the economy: risky human capital, risky physical capital and riskfree bonds. Our setup is such that, once portfolio allocation decisions are made, household consumption and savings policies are linear age-dependent functions of wealth, cf. Merton (1969) and Samuelson (1969). Therefore, conditional on expectations on the evolution of aggregate prices, the household problem is easy to solve. This feature of the model is particularly useful because it enables us to solve a large-scale OLG model with rather complex dynamics without incurring tremendous computational costs. On the firm side, the model is standard.

\subsection{Risk and Time}

Time is discrete and runs from $t=0, \ldots, \infty$. Aggregate uncertainty is represented by an event tree. The economy starts with some fixed event $\lambda_{0}$, and each node of the tree is a history of exogenous shocks $\lambda^{t}=\left(\lambda_{0}, \lambda_{1}, \ldots, \lambda_{t}\right)$. The shocks are assumed to follow a Markov chain with finite support $L$ and strictly positive transition matrix П. For notational convenience, we only index variables by time thereby suppressing the dependency of variables on $\lambda^{t}$ but it is understood that all choice variables are functions of history. 


\subsection{Production}

Production takes place with a standard Cobb-Douglas production function with total output at time $t$ given by

$$
Y_{t}=z_{t} \cdot K_{t}^{\alpha} \cdot\left(\Upsilon_{t} \cdot H_{t}\right)^{1-\alpha}
$$

where $K_{t}$ is the aggregate stock of physical capital, $H_{t}$ is the aggregate stock of human capital, and $z_{t}$ is a stochastic shock to total factor productivity. $\Upsilon_{t}$ is a human capital augmenting productivity parameter which grows at the exogenous constant rate $g$ to capture the observed trend growth of GDP.

Profit maximization of firms leads to the standard first order conditions stating that marginal products equal returns minus depreciation:

$$
\begin{aligned}
& r_{t}^{K}=\alpha \cdot z_{t} \cdot\left(\frac{K_{t}}{\Upsilon_{t} \cdot H_{t}}\right)^{\alpha-1}-\delta_{t}^{K} \\
& r_{t}^{H}=\Upsilon_{t} \cdot(1-\alpha) \cdot z_{t} \cdot\left(\frac{K_{t}}{\Upsilon_{t} \cdot H_{t}}\right)^{\alpha} .
\end{aligned}
$$

Note that $r^{H}$ grows along with $\Upsilon$ over time while $r^{K}$ is trend-stationary. Following Krüger and Kübler (2006), Storesletten, Telmer, and Yaron (2007), Gomes and Michaelides (2008) and others we assume that the depreciation rate of physical capital, $\delta_{t}^{K}$, is stochastic.

The capital stock, $K_{t}$, is financed by issuing stocks and bonds in quantities $S_{t}$ and $B_{t}$, so that $K_{t}=S_{t}+B_{t}=S_{t}(1+\ell)$ where $\ell$ is an exogenous and constant leverage ratio (debt-equity ratio). Accordingly, the firm only decides on aggregate capital and not on the capital structure. We borrow this specification from the finance literature, cf., e.g., Boldrin, Christiano, and Fisher (1995) and Croce (2014). It allows us to keep the depreciation shocks, which drive stock return volatility, small in the calibration. This is desirable, because large depreciation shocks imply unrealistically large fluctuations on the real side of the economy. The leveraged stock return is

$$
r_{t}^{s}=r_{t}^{K}+\ell\left(r_{t}^{K}-r_{t}^{f}\right)
$$

Accordingly, leverage ceteris paribus increases the mean and the variance of stock 
returns.

\subsection{Demographics}

The economy is populated with $J+1$ overlapping generations and the underlying population dynamics is the exogenous driving force of the model. Households enter the model at the age of $20(j=0)$ and live at most until turning $101(j=J+1=81)$. Population of age $j$ in time period $t$ is given recursively as

$$
N_{t, j}= \begin{cases}N_{t-1, j-1} \cdot \varsigma_{t-1, j-1} & \text { for } j=1, \ldots, J \\ \sum_{l=0}^{j_{f}} f_{t-20, l} \cdot N_{t-20, l} & \text { for } j=0\end{cases}
$$

where $\varsigma_{t, j}$ and $f_{t, j}$ denote time and age-specific survival and fertility rates, respectively. $j_{f}$ is the age of menopause. Processes governing mortality and fertility are assumed to be non-stochastic.

\subsection{Preferences}

We assume Epstein-Zin-Weil recursive preferences (Epstein and Zin 1989; Epstein and Zin 1991; Weil 1989). Let $\theta$ be a measure of risk-aversion and $\xi$ denote the elasticity of inter-temporal substitution. Epstein-Zin preferences then write as

$$
u_{t, j}=\left[c_{t, j}^{\frac{1-\theta}{\gamma}}+\beta \cdot\left(\mathbb{E}_{t, j}\left[\varsigma_{t, j} \cdot u_{t+1, j+1}^{1-\theta}\right]\right)^{\frac{1}{\gamma}}\right]^{\frac{\gamma}{1-\theta}}
$$

where $\gamma \equiv(1-\theta) /(1-1 / \xi) .0<\beta<1$ is the standard discount factor. For $\theta=1 / \xi$ we have $\gamma=1$ and are back at standard CRRA preferences. $\beta$ is the raw time discount factor and $c_{t, j}$ is consumption at time $t$, age $j . \mathbb{E}_{t, j}$ is the expectations operator and expectations are taken with respect to idiosyncratic shocks to human capital and aggregate shocks to productivity and physical capital depreciation conditional on information at time $t$, age $j$. As $\varsigma_{t, J}$ equals 0 for all $t$, equation (5) implies that $u_{J}=c_{J}$. Also observe that $u_{t, j}>0$ for $c_{t, j}>0 .{ }^{11}$

\footnotetext{
${ }^{11}$ We assume that the payoff in the event of death is $x=0$ with utility from death $\Gamma(x)=0$ so that we preserve homotheticity. The term inside the EZ aggregator accordingly writes as $\varsigma_{t, j} \cdot u_{t+1, j+1}^{1-\theta}+\left(1-\varsigma_{t, j}\right) \Gamma(x)=\varsigma_{t, j} \cdot u_{t+1, j+1}^{1-\theta}$. For our measure of risk aversion with respect to consumption risk we shall later require $\theta \geq 1$. This means that we assume a different measure of
} 


\subsection{Endowments}

When entering the economy at age $j=0$, households are endowed with an initial level of human capital, $h_{t, 0}=h_{0}$ for all $t$ and financial wealth $k_{t, 0}=0$ (there are no bequest flows to households). Summing financial assets and human capital makes up households' total wealth. Each period, households choose to invest a fraction of their total wealth in financial assets and in human capital respectively. Let $i_{t, j}^{h}$ denote the amount of wealth invested in human capital.

Human capital earns a gross rate of return of $r_{t}^{H}$ which is the marginal product of human capital. The term $r_{t}^{H} \cdot h_{t, j}$ can be understood as gross earnings of a household at age $j$ in period $t$. We assume that human capital depreciates at the individual level by the age-specific deterministic rate $\delta_{j}^{h}$. The age-profile of $\left\{\delta_{j}^{h}\right\}_{j=1}^{j_{r}}$ enables us to calibrate the model such that it mimics decreasing returns to human capital accumulation as assumed elsewhere in the literature (e.g., Huggett, Ventura, and Yaron (2011)). We assume the following functional form

$$
\delta_{j}^{h}=-\chi_{0}+\exp \left(\chi_{1} \cdot j\right), \quad \chi_{0}>0, \chi_{1} \geq 0,
$$

which is monotonically increasing in $j$ so that $1-\chi_{0} \leq \delta_{j}^{h} \leq \delta_{j+1}^{h}$ for all $j$. $\chi_{1}$ is the rate at which the household's human capital depreciation accelerates when getting older.

After the return to human capital is paid the household is hit by an additive idiosyncratic shock to its human capital holdings:

$$
\eta_{t} \sim \mathcal{D}\left(0, \sigma^{2}\left(\lambda_{t}\right)\right)
$$

where $\mathcal{D}$ is some distribution with mean zero, further specified in Section 3. Although the shock is idiosyncratic, it depends on the current state of the economy, $\lambda_{t}$, because, as further discussed below, the variance of the idiosyncratic human capital shock, $\sigma_{t}^{2}$, depends on the current state of the economy.

Collecting these elements, the human capital accumulation equation in period $t$,

risk aversion with respect to death, $\tilde{\theta} \in(0,1)$, to be able to write $\Gamma(x)=x^{1-\tilde{\theta}}=0$, for $x=0$, cf. Hugonnier, Pelgrin, and St-Amour (2013) for a similar approach. For a rigorous discussion on Epstein-Zin-Weil utility and the value of life see, e.g., Córdoba and Ripoll (2016) and Bommier, Harenberg, and Legrand (2016). 
age $j$, is given by

$$
h_{t+1, j+1}=h_{t, j} \cdot\left(1-\delta_{j}^{h}+\eta_{t}\right)+\tilde{i}_{t, j}^{h}, \quad h_{t, j} \geq 0 \quad \forall t, j,
$$

where $\tilde{i}_{t, j}^{h} \equiv i_{t, j}^{h} / \Upsilon_{t} \cdot{ }^{12}$ Note that all variables in (8) are trend-stationary. ${ }^{13}$

With respect to financial wealth $k_{t, j}$, the household faces a portfolio decision between risky and one period ahead risk-free financial assets, which we denote in the following by risky equity and risk-free bonds respectively, hence $k_{t, j}=s_{t, j}+b_{t, j}$ where $s_{t, j}$ are holdings of stocks when entering period $t$, age $j$ and $b_{t, j}$ are bonds. The dynamic financial asset accumulation equation in period $t$, age $j$, is accordingly given by

$$
k_{t+1, j+1}=s_{t+1, j+1}+b_{t+1, j+1}=s_{t, j}\left(1+r_{t}^{s}\right)+b_{t, j}\left(1+r_{t}^{f}\right)+h_{t, j} \cdot r_{t}^{H}-i_{t, j}^{h}-c_{t, j} .
$$

Let $\alpha_{t, j}^{s}=\frac{s_{t, j}}{k_{t, j}}$ be the fraction of holdings of risky equity in period $t$, age $j$. Then $\alpha_{t, j}^{b}=$ $\frac{b_{t, j}}{k_{t, j}}=1-\alpha_{t, j}^{s}$ is the fraction of holdings in bonds. We can then rewrite the dynamic asset budget constraint as

$$
k_{t+1, j+1}=k_{t, j} \cdot\left(1+r_{t}^{f}+\alpha_{t, j}^{s} \cdot\left(r_{t}^{s}-r_{t}^{f}\right)\right)+h_{t, j} \cdot r_{t}^{H}-i_{t, j}^{h}-c_{t, j} .
$$

\subsection{Transformations and Recursive Household Problem}

Transformations. To prepare the closed form solutions of the household model stated in the subsequent proposition, detrend the dynamic budget constraint (9) by dividing through the deterministic trend $\Upsilon_{t}$ to get

$$
\tilde{k}_{t+1, j+1}=\frac{1}{1+g}\left(\tilde{k}_{t, j} \cdot\left(1+r_{t}^{f}+\alpha_{t, j}^{s} \cdot\left(r_{t}^{s}-r_{t}^{f}\right)\right)+h_{t, j} \cdot \tilde{r}_{t}^{h}-\tilde{i}_{t, j}^{h}-\tilde{c}_{t, j}\right) .
$$

\footnotetext{
${ }^{12}$ We assume that costs for human capital investment, $i_{t}^{h}$, grow with the same rate as $\Upsilon_{t}$.

${ }^{13}$ As the return to human capital $r_{t}^{H}$ already exhibits a trend growth along with $\Upsilon_{t}$, human capital must be trend stationary in order to assure that gross human capital earnings, $h_{t, j} \cdot r_{t}^{H}$, grow at the same rate as $\Upsilon_{t}$ over time.
} 
where $\tilde{k}_{t, j}=\frac{k_{t, j}}{\Upsilon_{t}}, \tilde{c}_{t, j}=\frac{c_{t, j}}{\Upsilon_{t}}$ and $\tilde{r}_{t}^{h}=\frac{r_{t}^{h}}{\Upsilon_{t}}$. Next, add $\frac{1}{1+g}$ times equation (8) to the above to get

$$
\begin{aligned}
& \tilde{k}_{t+1, j+1}+\frac{h_{t+1, j+1}}{1+g}=\tilde{k}_{t, j} \cdot \frac{1}{1+g}\left(1+r_{t}^{f}+\alpha_{t, j}^{s} \cdot\left(r_{t}^{s}-r_{t}^{f}\right)\right)+ \\
& \frac{h_{t, j}}{1+g} \cdot\left(1+\tilde{r}_{t}^{h}-\delta_{j}^{h}+\eta_{t}\right)-\tilde{c}_{t, j} .
\end{aligned}
$$

The previous step is the first key transformation: linearity of the human capital accumulation function represented in (8) leads to the convenient property that investment expenses cancel out when consolidating the budget constraints.

Now, define total household wealth as the sum of holdings of financial and (growth rate adjusted) human wealth, $\tilde{w}_{t, j}=\tilde{k}_{t, j}+\frac{h_{t, j}}{1+g}$. Further, denoting by

$$
\begin{aligned}
\hat{\alpha}_{t, j}^{s} & \equiv \frac{\alpha_{t, j}^{s} \tilde{k}_{t, j}}{\tilde{w}_{t, j}} \\
\hat{\alpha}_{t, j}^{h} & \equiv \frac{h_{t, j} /(1+g)}{\tilde{w}_{t, j}}
\end{aligned}
$$

the period $t$, age $j$ holdings of stocks relative to total wealth, respectively the holdings of human wealth relative to total wealth, and by

$$
1+\hat{r}_{t, j}^{h} \equiv(1+g)\left(1+\tilde{r}_{t}^{h}-\delta_{j}^{h}+\eta_{t}\right)
$$

a growth rate adjusted gross return on human capital, rewrite (11) in terms of total wealth accumulation as

$$
\tilde{w}_{t+1, j+1}=\tilde{w}_{t, j} \cdot \frac{1}{1+g}\left(1+r_{t}^{f}+\hat{\alpha}_{t, j}^{s} \cdot\left(r_{t}^{s}-r_{t}^{f}\right)+\hat{\alpha}_{t, j}^{h} \cdot\left(\hat{r}_{t}^{h}-r_{t}^{f}\right)\right)-\tilde{c}_{t, j}
$$

Finally, define the gross portfolio return as

$$
\hat{r}_{t} \equiv r_{t}^{f}+\hat{\alpha}_{t, j}^{s} \cdot\left(r_{t}^{s}-r_{t}^{f}\right)+\hat{\alpha}_{t, j}^{h} \cdot\left(\hat{r}_{t}^{h}-r_{t}^{f}\right)
$$

and let cash-on-hand as wealth cum interest be $\tilde{x}_{t, j} \equiv \tilde{w}_{t, j}(1+\hat{r})$. With this definition rewrite (9) as

$$
\tilde{x}_{t+1, j+1}=\left(\tilde{x}_{t, j}-\tilde{c}_{t, j}\right) \cdot \frac{1}{1+g} \cdot\left(1+\hat{r}_{t+1}\right)
$$


Going from (13) to (14) is the second key transformation. As a consequence of this transformation all additive terms have vanished. This, in combination with homothetic preferences, will give rise to the closed form solutions stated in the subsequent proposition. Also notice that period $t$ age $j$ choice variables are $\tilde{c}_{t, j}, \tilde{x}_{t+1, j+1}$ as well as the portfolio shares $\hat{\alpha}_{t+1, j+1}^{s}, \hat{\alpha}_{t+1, j+1}^{h}$ which together determine the period $t+1$, age $j+1$ holdings of bonds, stocks and human capital.

Recursive Household Problem. We now define the household problem recursively. It is convenient to express next period's values with symbol ', irrespective of whether they are only time-dependent or both, age- and time-dependent. The states of the household problem are the exogenous states $j, t$, and $\lambda$, the endogenous idiosyncratic state of (de-trended) cash-on-hand, $\tilde{x}$, as well as the distribution of (de-trended) cash-on-hand, $\Phi$, which is the endogenous aggregate state of the economy. The associated law of motion is $\Phi^{\prime}=\Phi\left(\Phi, \lambda, \lambda^{\prime}, N^{\prime}\right)$. The existence of aggregate shocks implies that $\Phi$ evolves stochastically over time. Notice that $\lambda^{\prime}$ is a determinant of $\Phi^{\prime}$ because it determines the realizations of $r^{K \prime}, r^{s \prime}$ and $r^{H \prime}$. A change in demography, $N^{\prime}$, induces a transition of the economy from an initial stationary equilibrium to another. The (de-trended) household problem at age $j$ in period $t$ is then given by

$$
\begin{aligned}
v(\tilde{x}, \lambda, \Phi) & =\max _{\tilde{c}, \tilde{x}^{\prime}, \widehat{\alpha}^{\prime \prime}, \widehat{\alpha}^{h \prime}}\left\{\tilde{c}^{\frac{1-\theta}{\gamma}}+\widehat{\beta} \cdot\left(\mathbb{E}\left[v^{\prime}\left(\tilde{x}^{\prime}, \lambda^{\prime}, \Phi^{\prime}\right)^{1-\theta}\right]\right)^{\frac{1}{\gamma}}\right\}^{\frac{\gamma}{1-\theta}} \\
\text { s.t. } & \tilde{x}^{\prime}=\frac{1}{1+g} \cdot(\tilde{x}-\tilde{c}) \cdot\left(1+\widehat{r}^{\prime}\right), \tilde{x}_{0}>0 \text { given } \\
\hat{r}^{\prime} & \equiv r^{f^{\prime}}+\hat{\alpha}^{s^{\prime}} \cdot\left(r^{s^{\prime}}-r^{f^{\prime}}\right)+\hat{\alpha}^{h^{\prime}} \cdot\left(\hat{r}^{h^{\prime}}-r^{f^{\prime}}\right) \\
& \Phi^{\prime}=\Phi\left(\Phi, \lambda, \lambda^{\prime}, N^{\prime}\right), N^{\prime} \text { given } \\
& \pi\left(\lambda^{\prime} \mid \lambda\right), \lambda_{0} \text { given } \\
& \eta \mathcal{D}\left(0, \sigma^{2}(\lambda)\right) .
\end{aligned}
$$

where $\widehat{\beta} \equiv \beta \cdot \varsigma^{\frac{1}{\gamma}} \cdot(1+g)^{\frac{1-\theta}{\gamma}}$.

The expectations above are taken with respect to the realization of tomorrow's aggregate state $\lambda^{\prime}$ conditional on state $\lambda$ today and the realization of tomorrow's idiosyncratic shock, $\eta^{\prime}$, conditional on today's shock $\eta$. Note that $\lambda^{\prime}$ determines the shock to technology, $z^{\prime}$, the shock to physical capital depreciation, $\delta^{K \prime}$, and the 
variance of the idiosyncratic human capital depreciation shock, $\sigma^{2 \prime}$.

Using results derived in Samuelson (1969) we can next state the following properties of the optimal policy functions:

Proposition 1. Denote by $\widehat{\alpha}^{s * \prime}$ and $\widehat{\alpha}^{h * \prime}$ the optimal portfolio decisions that are the solutions to

$$
\begin{aligned}
& \mathbb{E}\left[\left(m^{\prime}\right)^{1-\theta-\gamma}\left(1+\widehat{r}^{\prime}\right)^{-\theta}\left(r^{s \prime}-r^{f \prime}\right)\right]=0 \\
& \mathbb{E}\left[\left(m^{\prime}\right)^{1-\theta-\gamma}\left(1+\widehat{r}^{\prime}\right)^{-\theta}\left(\widehat{r}^{h \prime}-r^{f \prime}\right)\right]=0
\end{aligned}
$$

where $m^{\prime}$ denotes next period's marginal propensity to consume out of (de-trended) cash-on-hand next period, $\tilde{x}^{\prime}$. Then the optimal (de-trended) consumption function is linear in cash-on-hand,

$$
\tilde{c}=m \cdot \tilde{x} .
$$

The marginal propensity to consume out of cash-on-hand is given by

$$
m=\frac{\left[\beta^{\gamma} \cdot \varsigma \cdot \wp\right]^{\frac{1}{1-\theta-\gamma}}}{1+\left[\beta^{\gamma} \cdot \varsigma \cdot \wp\right]^{\frac{1}{1-\theta-\gamma}}} \quad \text {, where } \wp \equiv \mathbb{E}\left[\left(m^{\prime}\right)^{1-\theta-\gamma} \cdot\left(1+\widehat{r}^{\prime}\right)^{1-\theta}\right]
$$

Proof. See Section A.1 in the Appendix.

Note that portfolio decisions do not depend on cash-on-hand, $\tilde{x}$, and consumption is linear in current cash-on-hand. These features are a consequence of the assumed homotheticity of preferences and are particularly useful in the numerical solution of the simulation model. In addition, linearity of policy functions implies that we do not need to break down the wealth distribution into idiosyncratic characteristics other than age.

\subsection{Government}

The government taxes accidentally bequeathed wealth of departed households and uses it for government consumption. For simplicity we assume that the tax rate on bequests is $100 \%$. Note that the government receives bequeathed wealth cum 
interest in period $t+1$.

$\tilde{G}_{t+1}=\frac{1}{1+g} \cdot \sum_{j=0}^{J} N_{t, j} \cdot\left(1-\varsigma_{t, j}\right) \cdot \tilde{x}_{t, j} \cdot\left(1-m_{t, j}\right) \cdot\left(1+r_{t+1}^{f}+\alpha_{t+1, j+1}^{s} \cdot\left(r_{t+1}^{s}-r_{t+1}^{f}\right)\right)$

\subsection{Equilibrium}

Equilibrium in the economy is defined recursively and presented in de-trended form, cf. Section 2.6. It requires market clearing in all periods while optimal decisions and aggregation conditions have to hold. In the following, ' indicates next period's variables while we make the dependency on age, $j$, explicit.

Definition 1. Given the initial distribution over cash-on-hand, $\Phi_{0}$, a recursive competitive equilibrium is a value function $v(j, \tilde{x}, \lambda, \Phi)$ and policy functions, $\widehat{\alpha}^{s \prime}\left(j, \lambda, \lambda^{\prime}, \Phi^{\prime}\right)$, $\widehat{\alpha}^{h \prime}\left(j, \lambda, \lambda^{\prime}, \Phi^{\prime}\right), c\left(j, \lambda, \lambda^{\prime}, \Phi^{\prime}\right), x^{\prime}\left(j, \lambda, \lambda^{\prime}, \Phi^{\prime}\right)$, for the household, policy functions for the firm, $\tilde{K}(\lambda, \Phi), H(\lambda, \Phi)$, pricing functions $r^{s}(\lambda, \Phi), r^{H}(\lambda, \Phi), r^{f \prime}(\lambda, \Phi)$, the demographic distribution, $N$, the wealth distribution, $\Phi$, and its associated (aggregate) law of motion, $\Phi\left(\Phi, \lambda, \lambda^{\prime}, N^{\prime}\right)$, such that for all $(\lambda, \Phi)$

1. $v(\cdot), \tilde{x}(j, \lambda, \Phi), \tilde{c}(j, \tilde{x}, \lambda, \Phi), \widehat{\alpha}^{s \prime}(\cdot), \widehat{\alpha}^{h \prime}(\cdot), m(\cdot)$ are measurable, $v(\cdot)$ satisfies the household's recursive problem, and $\widehat{\alpha}^{s \prime}(\cdot), \widehat{\alpha}^{h \prime}(\cdot), m(\cdot)$ are the associated policy functions following from the conditions in Proposition 1, given $\mathbb{E}\left[r^{s^{\prime}}\left(\lambda^{\prime}, \Phi\left(\Phi, \lambda, \lambda^{\prime}, N^{\prime}\right)\right)\right], \mathbb{E}\left[\widehat{r}^{h^{\prime}}\left(j+1, \eta^{\prime}, \lambda^{\prime}, \Phi\left(\Phi, \lambda, \lambda^{\prime}, N^{\prime}\right)\right)\right], r^{f^{\prime}}(\cdot)$ and $\tilde{x}(\cdot)$,

2. firms behave optimally as according to equations (2),

3. government consumption financed by accidental bequests fulfills equation (18), 
4. markets clear:

$$
\begin{aligned}
\tilde{B}^{\prime}(\cdot)=\tilde{K}^{\prime}(\cdot) \cdot \frac{\ell}{1+\ell} & =\frac{1}{1+g} \cdot \sum_{j=0}^{J} N(j) \cdot \tilde{x}(j, \cdot) \cdot(1-m(j, \cdot)) \cdot\left(1-\widehat{\alpha}^{s \prime}(j, \cdot)-\widehat{\alpha}^{h \prime}(j, \cdot)\right) \\
\tilde{S}^{\prime}(\cdot)=\tilde{K}^{\prime}(\cdot) \cdot \frac{1}{1+\ell} & =\frac{1}{1+g} \cdot \sum_{j=0}^{J} N(j) \cdot \tilde{x}(j, \cdot) \cdot(1-m(j, \cdot)) \cdot \widehat{\alpha}^{s \prime}(j, \cdot) \\
H(\cdot) & =\sum_{j=0}^{J} N(j) \cdot \frac{\tilde{x}(j,)}{1+\widehat{r}(j, \cdot)} \cdot \widehat{\alpha}^{h}(j, \cdot) \\
\tilde{Y}(\lambda, \Phi) & =\tilde{C}(\lambda, \Phi)+\tilde{G}(\lambda, \Phi)+\tilde{I}^{K}(\lambda, \Phi)+I^{h}(\lambda, \Phi) .
\end{aligned}
$$

The bond price $q^{f}(\lambda, \Phi):=\left(1+r^{f^{\prime}}(\lambda, \Phi)\right)^{-1}$ is determined such that it clears the bond market in period t. (19d) is the aggregate resource constraint which is derived in Section A.2 of the Appendix,

5. the aggregate law of motion $H$ determines the transition of the distribution according to

$$
\Phi^{\prime}=H\left(\Phi, \lambda, \lambda^{\prime}, N^{\prime}\right)
$$

It is generated by the exogenous population dynamics, the exogenous stochastic processes and the endogenous asset accumulation decisions as captured by the policy functions.

Definition 2. A stationary recursive competitive equilibrium is a special case of the equilibrium described above. It is characterized by time-constant individual policy functions $m(\cdot)$, $\widehat{\alpha}^{s \prime}(\cdot)$, $\widehat{\alpha}^{h \prime}(\cdot)$, and a time-constant aggregate law of motion $\Phi(\cdot)$. This requires a time-constant demographic distribution, $N$.

\section{Solution Method and Calibration}

Solution Method. We solve an approximate rational expectations equilibrium of definition 1 by applying a variant of the Krusell and $\operatorname{Smith}(1997,1998)$ method. Specifically, we formulate three laws of motion: for the aggregate capital stock, the 
ratio of aggregate physical capital to aggregate human capital and the expected equity premium. We solve for the coefficients of these aggregate laws of motion in both an initial year 1960 as well as a final year 2500 stationary equilibrium. For the transition between these two equilibria, we parameterize transitional laws of motion with flexible time polynomials. All details are described in Appendix B.1.

Calibration. Calibration of the model is in part by reference to other studies and in part by informal matching of moments procedures. The period length is one year. Table 1 summarizes structural model parameters where target values refer to year 2010. The additional parameters governing stochastic and demographic processes are described in the text.

Table 1: First and Second Stage Parameters

\begin{tabular}{lccc}
\hline \hline Parameter & Value & Target & Target Source, Comment \\
\hline \hline Firm sector & & & \\
Capital share: $\alpha$ & 0.36 & $1^{s t}$ stage & wage share (NIPA) \\
Technological progress: $g$ & 0.018 & $1^{s t}$ stage & TFP growth (NIPA) \\
Leverage ratio: $\ell$ & 0.67 & $1^{\text {st }}$ stage & RZ \\
Mean depreciation rate $K: \delta_{0}^{K}$ & 0.086 & $r^{f}=0.013$ & PST, Shiller $(2015)$ \\
\hline Households & & & \\
Life cycle: $j=\left\{0, j_{r}, J\right\}$ & $\{0,45,80\}$ & $1^{s t}$ stage & biological age: $\{20,65,100\}$ \\
Elasticity inter-temp. substit., $\xi$ & 1.5 & $1^{s t}$ stage & Bansal and Yaron $(2004)$ \\
Endowment: $\left\{h_{0}, k_{0}\right\}$ & $\{1.0,0.0\}$ & $1^{s t}$ stage & normalization \\
Time discount factor: $\beta$ & 0.936 & $K / Y=2.65$ & NIPA \\
Relative risk aversion: $\theta$ & 8.4 & $r^{s}-r^{f}=0.062$ & PST \\
Depreciation rate $h:\left\{\chi_{0}, \chi_{1}\right\}$ & $\{0.976,0.0007\}$ & $\left\{r^{H} \cdot h_{j}\right\}_{j=20}^{64}$ & PSID \\
\hline \hline
\end{tabular}

Source: Baseline model: The target year is 2010. Notes: RZ $\hat{=}$ Rajan and Zingales (1995). PST $\hat{=}$ Piazzesi, Schneider, and Tuzel (2007). We target the average of the post-Second World War risk-free rates of PST and Shiller (2015).

The time- and age-specific demographic data for the population dynamics in (4) are based on (Human Mortality Database 2008) and the United Nations' population projections (United Nations 2007).

We assume that aggregate risk is driven by a four state Markov chain with support $L=\left\{\lambda_{1}, \ldots, \lambda_{4}\right\}$ and transition matrix $\Pi=\left(\pi_{i k}\right)$. Each aggregate state maps into a combination of low or high technology shocks and low or high physical 
capital depreciation. Precisely, we assume that

$$
z_{t}=z\left(\lambda_{t}\right)=\left\{\begin{array}{l}
z_{0}(1+\bar{z}) \text { for } \lambda \in \lambda_{1}, \lambda_{2} \\
z_{0}(1-\bar{z}) \text { for } \lambda \in \lambda_{3}, \lambda_{4}
\end{array} \quad, \delta_{t}^{k}=\delta^{k}\left(\lambda_{t}\right)=\left\{\begin{array}{l}
\delta_{0}^{k}+\bar{\delta}^{k} \text { for } \lambda \in \lambda_{1}, \lambda_{3} \\
\delta_{0}^{k}-\bar{\delta}^{k} \text { for } \lambda \in \lambda_{2}, \lambda_{4} .
\end{array}\right.\right.
$$

One feature specific to the model is that the endogenous fluctuations generated by financial savings and human capital accumulation are higher than in the standard model with exogenous labor income. Therefore, the auto-correlation of the exogenous technology shock process, $\rho^{z}$, and the probability of a high (low) depreciation state conditional on being in a low (high) technology state, $\rho^{\delta}$, must be lower than in the standard model. We assume $\rho^{\delta}=0.6$ and $\rho^{z}=0.7$ which comes close to Gomes and Michaelides (2008) who use 0.5 and 0.67 respectively. $\bar{z}$ is set to 0.02 which results in a standard deviation of GPD growth of $4 \%$ and a standard deviation of consumption growth of $3.8 \%$. This is slightly higher than the $3 \%$ measured usually in the data. The standard deviation of the shock to the depreciation rate of physical capital is set to $\bar{\delta}^{k}=0.1$ such that the model matches the standard deviation of the stock return in the data of about $16.7 \%$ (cf., e.g., Shiller 2015).

The value of the capital share parameter, $\alpha=0.36$, is based on an estimation of the aggregate production function for the US, cf. Krüger and Ludwig (2007), and lies in the usual range considered in the literature. The value of the mean depreciation rate of physical capital, $\delta_{0}^{K}=0.086$, lies at the upper end of the range of empirical estimates and leads to a risk-free interest rate of $1.3 \%$. We assume that the representative firm keeps an exogenous fixed leverage ratio, $\ell:=\frac{B}{S}$, which is set to the empirically observed value, 0.67 (cf. Rajan and Zingales 1995).

The value of households' raw time discount factor, $\beta=0.936$, is at the lower range of values considered in the literature. It yields a capital-output ratio of 2.65, as measured in NIPA data, cf., e.g., Ludwig, Schelkle, and Vogel (2012). The elasticity of inter-temporal substitution, $\xi$, equals 1.5. It lies in the range considered in the asset pricing literature (cf. the discussion in Bansal and Yaron (2004, pp. 149293)) and results in a hump-shaped consumption profile which is in line with the data, cf. Fernández-Villaverde and Krüger (2006). While being mostly flat between ages 45 and 65 the peak lies at around the age of 55 . The value of the coefficient of relative risk aversion, $\theta=8.4$, must be considered high relative to the literature. However, Mehra and Prescott (1985) argue that the upper bound of reasonable 
values of the parameter of risk aversion is 10 . With this value, the model is able to generate an empirically observed equity premium of about $6.2 \%$.

Due to the homotheticity of preferences, the initial level of human capital $h_{0}$ is irrelevant and we normalize human capital by setting $h_{0}=1$. We calibrate the human capital depreciation rate, $\delta^{h}$, by setting the corresponding parameters, $\chi_{0}$ and $\chi_{1}$, such that the model matches observed wage profiles based on PSID data, as estimated in Ludwig, Schelkle, and Vogel (2012). Idiosyncratic shocks to human capital, $\eta$, are uncorrelated but the variance of $\eta$ depends on the current state of the economy which has been documented in the data and used in the asset pricing literature (cf. Storesletten, Telmer, and Yaron (2004) and Constantinides and Duffie (1996) respectively). We follow the approach of Storesletten, Telmer, and Yaron (2007) and set the standard deviation $\sigma_{t}$ to

$$
\sigma_{t}=\sigma(\lambda)= \begin{cases}0.2 & \text { for } \lambda \in\left(\lambda_{1}, \lambda_{2}\right) \\ 0.1 & \text { for } \lambda \in\left(\lambda_{3}, \lambda_{4}\right)\end{cases}
$$

which is within the range considered in Krebs and Wilson (2004). ${ }^{14}$

\section{Results}

Throughout we present average profiles, averaged across stochastic simulations, see Appendix B.

\subsection{Cross-Sectional Profiles in 2010}

Figure 1 shows cross-sectional age profiles of the model economy in year 2010. The top left panel shows consumption and gross savings by age. Consumption is humpshaped as in the data (cf., e.g., Fernández-Villaverde and Krüger (2006)) and remains at its maximum level between 48 and 64. Gross savings exhibit the typi-

\footnotetext{
${ }^{14}$ This approach has recently been criticized by Guvenen, Ozkan, and Song (2014) who find that the left skewness of the earnings distribution, not its variance, is countercyclical. Since an increasing left skewness of incomes in recessions drives a relatively larger fraction of households into an area where the marginal utility from consumption is strongly convex, we conjecture that (a numerically costly) alternative calibration targeting higher moments of income processes would lead us to identify a lower value of the coefficient of risk aversion to match the same asset pricing moments.
} 
cal saving-dis-saving pattern as in standard life-cycle models. The top right panel depicts the portfolio allocation of households by age. Households enter their economically relevant lifetime with zero financial assets but positive human capital. Subsequently, the latter follows a hump-shaped pattern over the working life which results in a corresponding pattern in the age-earnings profile (bottom left panel). This is a target in the calibration.

The share of financial asset holdings in stocks, $\alpha_{t, j}^{s}$, is shown in the bottom right panel. To understand the life-cycle pattern, in particular the decrease during the working period, turn to equation (12a) according to which $\alpha_{t, j}^{s}=\hat{\alpha}_{t, j}^{s}\left(\frac{\tilde{k}_{t, j}}{\tilde{w}_{t, j}}\right)^{-1}$. The transformed portfolio share, $\hat{\alpha}_{t, j}^{s}$, is roughly constant over the life-cycle. This is a well-known feature of portfolio choice models such as ours, cf., e.g., Campbell and Viceira (2002, ch. 6). Horizon effects in our model arising from autocorrelated returns and the finite horizon of the life-cycle model are small, also see Barberis (2000). In consequence, the dynamics of $\alpha_{t, j}^{s}$ over the life-cycle are mainly driven by the dynamics of the share of financial wealth in total wealth, $\frac{\tilde{k}_{t, j}}{\tilde{w}_{t, j}}$. As households accumulate more and more financial wealth over their life-cycle and because human wealth is decumulated after about age 40, the share of financial wealth in total wealth is increasing over the life-cycle. This explains why the risky asset share (as of financial wealth) is decreasing. ${ }^{15}$ In retirement human capital drops to zero and so $\alpha_{t, j}^{s}$ drops to $\hat{\alpha}_{t, j}^{s} \cdot{ }^{16}$

\subsection{Macroeconomic Aggregates and Asset Returns}

We now turn to results on key macroeconomic aggregates and differential asset returns and how they are affected by the demographic transition. Figure 2 summarizes the key summary statistics on the demographic transition for the US economy, which we take as the exogenous driving force. The working age to population ratio - which

\footnotetext{
${ }^{15}$ As human capital decreases the portfolio becomes less diversified and the overall risk of the portfolio increases. In order to keep the overall risk of their portfolio down individuals therefore decrease their risky asset share.

${ }^{16}$ This life-cycle profile of the risky portfolio share is not consistent with average age profiles of stock holdings in the SCF. However, according to the empirical findings in Glover, Heathcote, Krueger, and Rios-Rull (2014), taking a broader perspective on risky net worth held by households which also includes residential and non-residential property and non-corporate business wealth, gives age profiles that are consistent with our simulated profiles. Future versions of this paper will take such a broader perspective.
} 
Figure 1: Cross-Sectional Profiles in 2010

(a) Consumption and Gross Savings

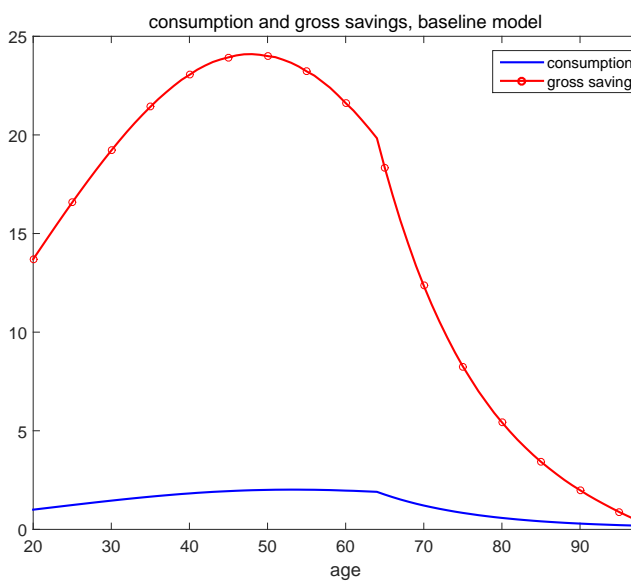

(c) Earnings (Index, Age 20=1)

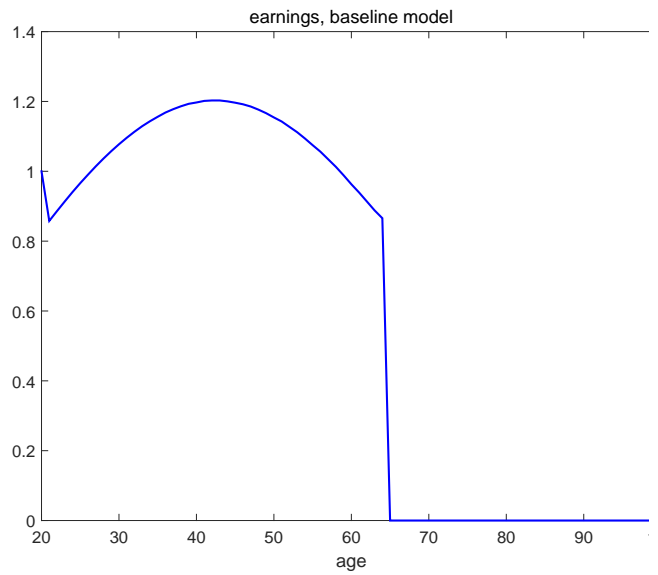

(b) Portfolio Allocation

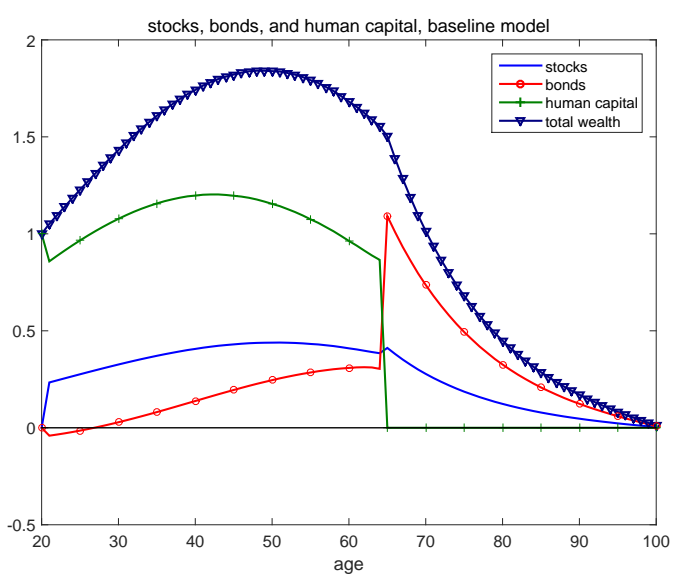

(d) Risky Share in Financial Assets

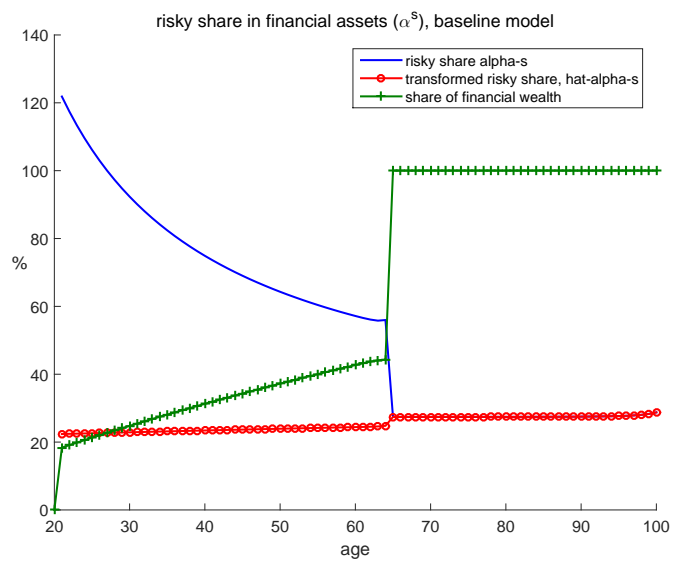

Notes: Baseline model in year 2010: Selected average cross-sectional age profiles. 
we define here as the ratio of the working population of age 20 to 64 to the total adult population of age 20 and above - is projected to decrease by about 10 percentage points until 2030. The mirror image of this development is the evolution of the old age dependency ratio - the ratio of the population of age 65 and older to the working age population - which is projected to increase by almost 20 percentage points over the same period.

Figure 2: Working Age-to-Population Ratio

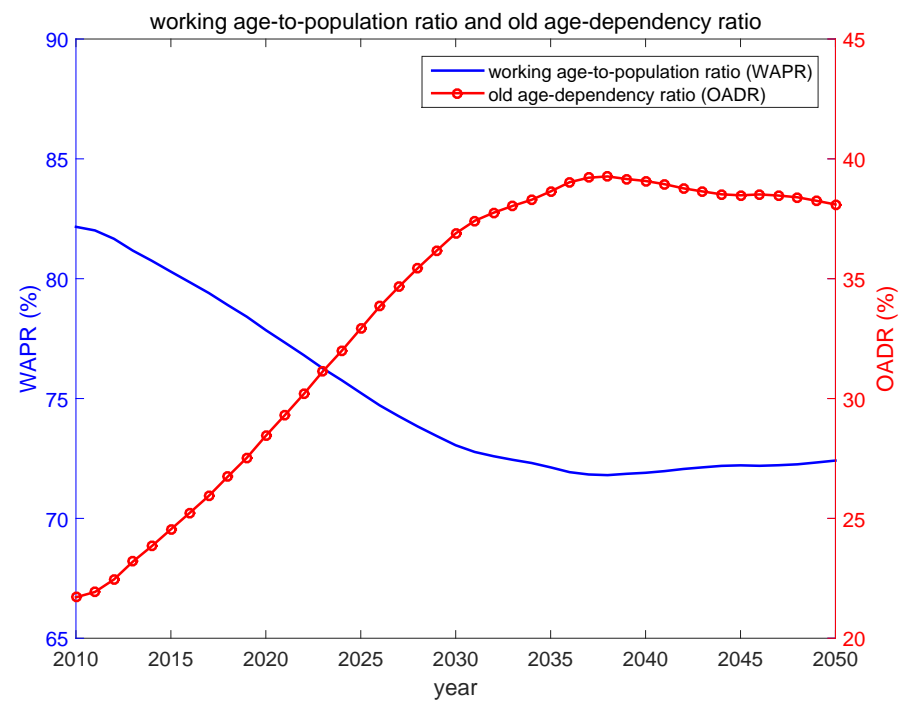

Source: Own calculations based on United Nations (2007) and Human Mortality Database (2008). Notes: The working age-to-population ratio equals the population at ages $20-64$ over the total population of the model economy. The retirement age of 65 is held fix over time.

When we analyze the macroeconomic consequences of these developments by using our model with endogenous human capital formation, we distinguish between two variants of our model. As a first variant we consider a specification where we hold constant the human capital shares, $\hat{\alpha}_{t, j}^{h}$, of year 1960 in all periods. We thereby approximate a model without human capital adjustments. ${ }^{17}$ Our second variant is the full-blown model with fully flexible human capital adjustments. The comparison across these two model variants enables us to illustrate the mitigating effects of endogenous human capital adjustments for the dynamics of aggregate measures and asset returns along the demographic transition. As both models are

\footnotetext{
${ }^{17}$ To preserve the closed form solutions in our model, we have to fix $\hat{\alpha}_{t, j}^{h}$ and cannot directly hold constant $h_{t, j}$. We therefore speak of an approximation to a model with constant human capital.
} 
extreme variants - on the one hand, the restricted model likely too severely restricts economic adjustments, on the other hand, the fully endogenous model overstates such adjustments because it does not feature any frictions on the market for human capital - our approach enables us to bracket the likely evolution of these variables over the next decades.

\subsubsection{Macroeconomic Aggregates}

We first turn in Figure 3 to showing the evolution of the ratio of physical capital to output, $K / Y$, and of human capital to output, $H / Y . K / Y$ is shown as blue solid lines (left scales) in the two panels of the figure whereas $H / Y$ is depicted on the right scales as green dashed lines. Conventional analyses suggest that aging induces a relative shortage of labor and a relative abundance of physical capital in the economy. This leads to an increase in the physical capital-output ratio and a decrease in the human capital-output ratio. Our model with fixed human capital shares, shown in Panel (a) of the figure, is in line with these conventional analyses. It predicts an increase of the capital output ratio from 2.65 to 2.81 until 2030, a change of roughly $6 \%$. Likewise the human capital to output ratio decreases substantially. With fully endogenous human capital adjustment, shown in Panel (b), we observe very mild changes in these variables over time. The endogenous adjustment of human capital dampens the reduction of the human capital to output ratio because human capital shares per worker go up. This also stabilizes output which in turn dampens the increase of the physical capital to output ratio.

Figure 4 shows the corresponding reaction of aggregate detrended per capita output. In this figure we ask how large the output losses from demographic change will be relative to a path with constant growth, i.e., relative to staying in the initial stationary equilibrium. In the model with fixed human capital shares, Panel (a), output losses from demographic change are quite strong. The reduction is by roughly $6 \%$ until 2035. In contrast, under flexible human capital adjustments, Panel (b), these output losses can be mitigated quite substantially and stand at only minus $2 \%$.

As the main insight of our analysis so far we therefore find that endogenous human capital choices will quite substantially mitigate the general equilibrium adjustments to demographic change. 
Figure 3: Macroeconomic Aggregates: Physical and Human Capital

(a) Fixed Human Capital Shares

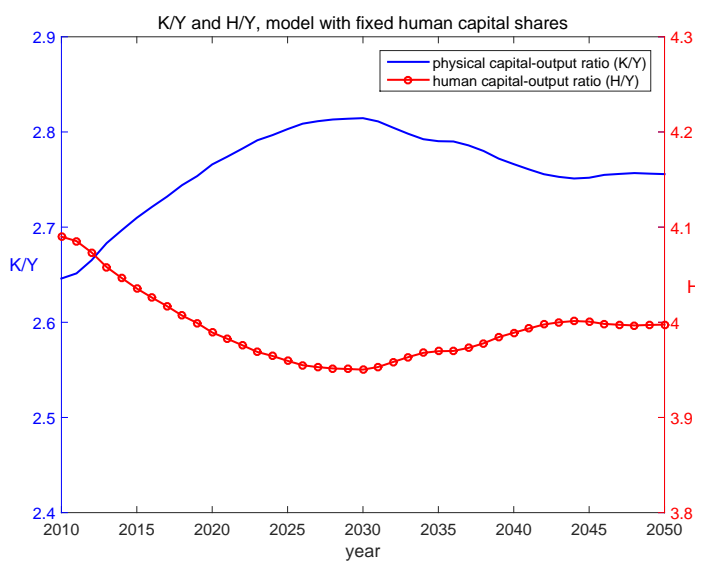

(b) Flexible Human Capital Adjustments

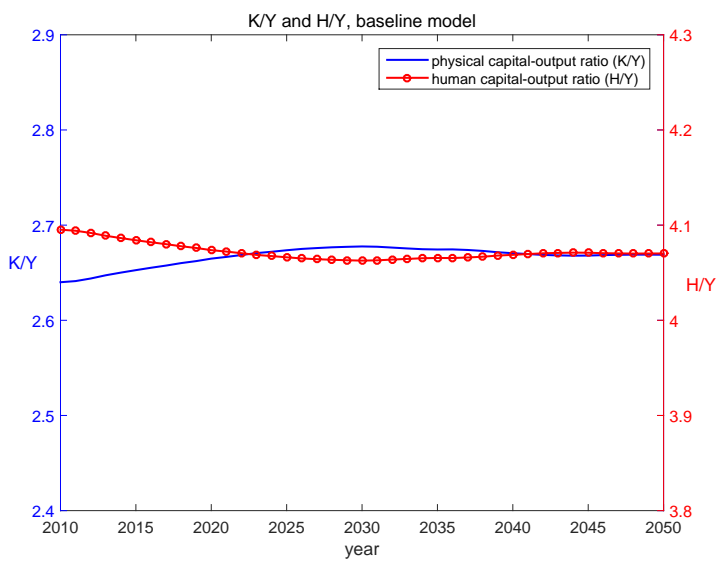

Notes: Model with fixed human capital shares, at respective values in 1960, in Panel (a) and flexible human capital adjustments in Panel (b).

Figure 4: Aggregate Output [Index, 2010=100]

(a) Fixed Human Capital Shares

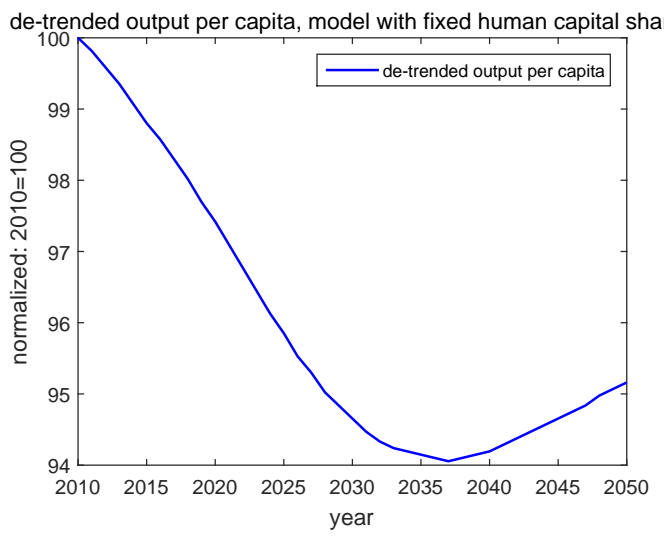

(b) Flexible Human Capital Adjustments

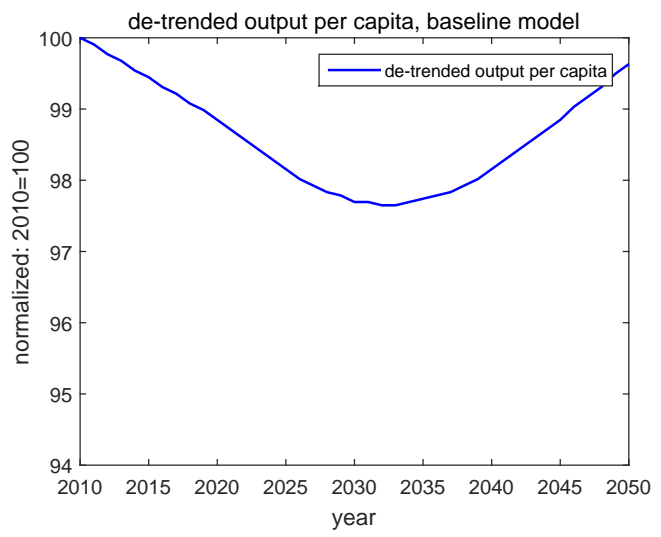

Notes: Model with fixed human capital shares, at respective values in 1960, in Panel (a) and flexible human capital adjustments in Panel (b). 


\subsubsection{Marginal Products and Asset Returns}

As shown in Figure 5, the shortage of labor (of human capital) translates into quite strong decreases in the marginal product of physical capital from $5 \%$ to $4.2 \%$ in our model with fixed human capital shares. Correspondingly, the marginal production of human capital increases substantially. Again, both these effects are substantially smaller with endogenous human capital adjustments.

Figure 5: Marginal Products

(a) Fixed Human Capital Shares

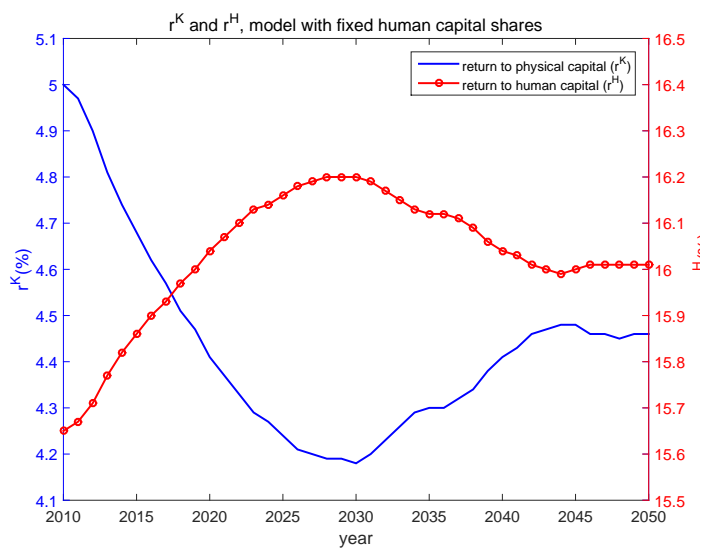

(b) Flexible Human Capital Adjustments

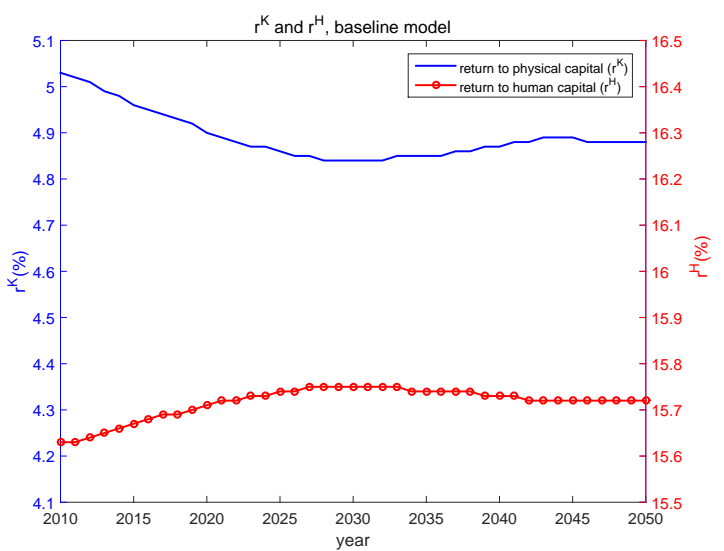

Notes: Model with fixed human capital shares, at respective values in 1960, in Panel (a) and flexible human capital adjustments in Panel (b).

We now turn to the key quantitative question of this paper, namely how the afore analyzed marginal products translate into risky stock returns and how demographic change affects the risk-free rate. Figure 6 accordingly plots the time paths for returns to equity (blue solid lines) and returns to bonds (green dashed lines). Both returns decline over time which corresponds to the result of a declining return to physical capital described above. Again effects are much larger in the model with constant human capital shares. These predictions suggest that low financial market returns can be expected for (many) decades to come, irrespective of the risk nature of the asset.

Importantly, the figure shows that the risk-free rate is predicted to decrease more strongly than the risky rate. Hence, the equity premium - the difference between the return to equity and the return to bonds - will increase. The equity premium 
Figure 6: Return to Equity and Risk-Free Rate

(a) Fixed Human Capital Shares

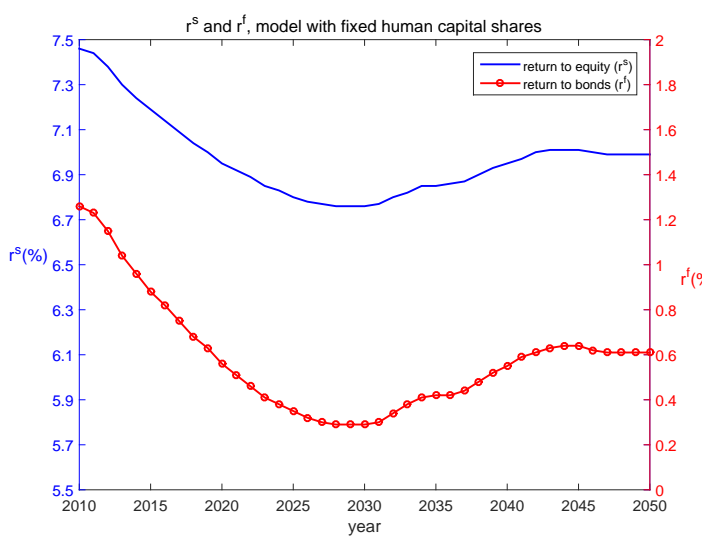

(b) Flexible Human Capital Adjustments

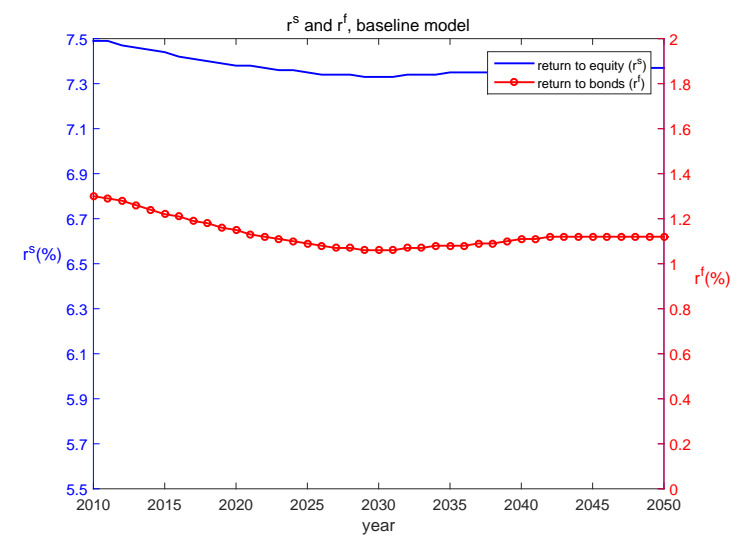

Notes: Model with fixed human capital shares, at respective values in 1960, in Panel (a) and flexible human capital adjustments in Panel (b).

increases by about 30 basis points until 2030 in the model with fixed human capital shares. This comes from the fact that old households hold relatively more bonds in their financial portfolio as was shown in Panel (d) of Figure $1 .{ }^{18}$ As the projected demographic evolution increases the share of the population in old age, this leads to a higher relative demand for bonds in the economy driving up bond prices and reducing bond returns more strongly than the return to equity.

Human capital adjustments work as an opposing force so that the effects on the equity premium are relatively mild in the model with fully flexible human capital. Higher human capital investments, in particular by young households, imply higher earnings along their working life, which is reinforced by the co-incident increase in the return to human capital, cf. Figure 5. This increases the share of human capital in total wealth and correspondingly reduces the share of financial wealth. Again relating back to equation (12a) according to which $\alpha_{t, j}^{s}=\hat{\alpha}_{t, j}^{s}\left(\frac{\tilde{k}_{t, j}}{\tilde{w}_{t, j}}\right)^{-1}$, we see that this will lead to an increase of holdings of stocks $\left(\alpha_{t, j}^{s}\right.$ increases, $\hat{\alpha}_{t, j}^{s}$ itself is relatively stable across human capital scenarios as well as over the life-cycle). This reduces the demand for bonds which stabilizes the equity premium relative to the model with fixed human capital shares.

\footnotetext{
${ }^{18}$ In fact, this includes a counteracting portfolio adjustment effect isolated in Kuhle (2008) which arises if the absolute return level drops which is the case here.
} 
Tables 2 summarizes the results on asset returns by reporting the corresponding numbers for the years 2010, 2030, and 2050 as well as the respective changes to the base year 2010 .

Table 2: Summary of Results on Asset Returns

\begin{tabular}{|c|c|c|c|c|c|c|}
\hline & $W A P R$ & $K / Y$ & $\overline{r^{f}}$ & $r^{s}$ & $\left\{\widehat{r}_{j}^{h}\right\}_{\text {avrg. }}$ & $E P$ \\
\hline \multicolumn{7}{|c|}{ Fixed Human Capital Shares } \\
\hline 2010 & $82.00 \%$ & 2.65 & $1.26 \%$ & $7.46 \%$ & $13.62 \%$ & $6.20 \%$ \\
\hline 2030 & $73.00 \%$ & 2.81 & $0.29 \%$ & $6.76 \%$ & $14.22 \%$ & $6.47 \%$ \\
\hline 2050 & $72.00 \%$ & 2.76 & $0.61 \%$ & $6.99 \%$ & $14.04 \%$ & $6.38 \%$ \\
\hline$\Delta_{\{2030-2010\}}$ & $-9.00 \% \mathrm{p}$ & $+6.03 \%$ & $-0.97 \% \mathrm{p}$ & $-0.70 \% \mathrm{p}$ & $+0.60 \% \mathrm{p}$ & $+0.27 \% \mathrm{p}$ \\
\hline$\Delta_{\{2050-2010\}}$ & $-10.00 \% \mathrm{p}$ & $+4.15 \%$ & $-0.65 \% \mathrm{p}$ & $-0.47 \% \mathrm{p}$ & $+0.42 \% \mathrm{p}$ & $+0.18 \% \mathrm{p}$ \\
\hline \multicolumn{7}{|c|}{ Flexible Human Capital Adjustments } \\
\hline 2010 & $82.00 \%$ & 2.65 & $1.30 \%$ & $7.49 \%$ & $11.64 \%$ & $6.19 \%$ \\
\hline 2030 & $73.00 \%$ & 2.68 & $1.06 \%$ & $7.33 \%$ & $11.81 \%$ & $6.27 \%$ \\
\hline 2050 & $72.00 \%$ & 2.67 & $1.12 \%$ & $7.37 \%$ & $11.80 \%$ & $6.25 \%$ \\
\hline$\Delta_{\{2030-2010\}}$ & $-9.00 \% \mathrm{p}$ & $+1.13 \%$ & $-0.24 \% \mathrm{p}$ & $-0.16 \% \mathrm{p}$ & $+0.17 \% \mathrm{p}$ & $+0.08 \% \mathrm{p}$ \\
\hline$\Delta_{\{2050-2010\}}$ & $-10.00 \% \mathrm{p}$ & $+0.75 \%$ & $-0.18 \% \mathrm{p}$ & $-0.12 \% \mathrm{p}$ & $+0.16 \% \mathrm{p}$ & $+0.06 \% \mathrm{p}$ \\
\hline
\end{tabular}

Notes: Baseline model in the main period of projection. $W A P R \widehat{=}$ working age-to-population ratio. $\left\{\widehat{r}_{j}^{h}\right\}_{\text {avrg. }} \widehat{=}$ average return to human capital of all agents alive. $E P:=r^{s}-r^{f}$. The top three lines show the values of the considered variables for the year 2010, 2030, and 2050 in percent. The bottom two rows show the percentage point $(\% p)$ change of the considered variables from 2010 to 2030 and 2010 to 2050.

\subsection{Consequences for Welfare}

We next investigate how these return dynamics translate into welfare consequences of demographic change. We follow Davila, Hong, Krusell, and Rios-Rull (2012), Harenberg and Ludwig (2015), and others, and measure welfare by the ex-ante expected utility at the beginning of a household's life, $\mathbb{E}\left[v_{\cdot, 0}\right]$. All households of a given cohort are ex-ante identical and turn heterogeneous along the life cycle due to idiosyncratic shocks to human capital. The welfare concept of ex-ante expected utility is the natural objective of a social planner who is behind the veil of ignorance (cf. Davila, Hong, Krusell, and Rios-Rull (2012, p. 2439)). As in Harenberg and Ludwig (2015) we take an ex-ante perspective and therefore compute the ex-ante expected utility by averaging across histories $\lambda^{t}$. 
Demographic change affects a household's welfare in two ways. The first effect arises from changes in survival probabilities which are exogenous in this model. The second effect stems from changing human capital and financial asset returns. We want to isolate the second effect. To do so we first compute welfare in a partial equilibrium variant of the model where we hold constant the aggregate law of motion of the economy (for the initial year 1960). We denote the ex-ante expected utility in this initial partial equilibrium by $\mathbb{E}\left[v_{t, 0}^{P E}\right]$. We then determine welfare in our full general equilibrium where aggregate laws of motion change accordingly. ${ }^{19}$ Finally, we measure the welfare effects of demographic change in terms of a consumption equivalent variation, i.e., we ask how much compensation in percent of consumption a household must receive in all periods of her lifetime in order to be indifferent between the worlds with and without demographic change. Based on the homotheticity of the value function, the consumption equivalent variation for a cohort born in $t$ can be computed as

$$
c e v_{t}:=\frac{\mathbb{E}\left[v_{t, 0}\right]}{\mathbb{E}\left[v_{t, 0}^{P E}\right]}-1
$$

Positive numbers therefore indicate cohorts that benefit (on average) from demographic change. We conduct these experiments for both human capital versions of the model.

Figure 7 shows resulting welfare effects of demographic change for all cohorts born in years 1960 to $2050 .^{20}$ Panel (a), for the model variant with fixed human capital shares, shows that the welfare effects of demographic change differ considerably across cohorts. Future cohorts born after 2018 benefit from the price effects induced by demographic change because they will be born into an environment with labor scarcity and high associated human capital returns. Older cohorts, especially all cohorts that are currently alive, lose form demographic change because of low asset returns in old age and relatively low human capital returns when they were young (at times when labor was still an abundant factor).

Panel (b) of the figure reveals three crucial findings for the model with flexible

\footnotetext{
${ }^{19}$ We simulate the two model variants using both, identical initial conditions and the identical 50000 time series of aggregate shock realizations. We compute the ex-ante expected utility as the average across these simulations.

${ }^{20}$ Recall that birth of a cohort occurs when individuals turn 20.
} 
human capital adjustments. First, welfare losses to old cohort are substantially lower because asset returns decrease less strongly, cf. Figure 6. Second, gains for future cohorts are smaller because the general equilibrium response of human capital returns is less strong, cf. Figure 5. Finally, the fraction of winners in the population increases: now, already cohorts born in 2005 and later (hence some cohorts already alive today) benefit from the demographic transition.

Figure 7: Welfare Effects of Demographic change

(a) Fixed Human Capital Shares

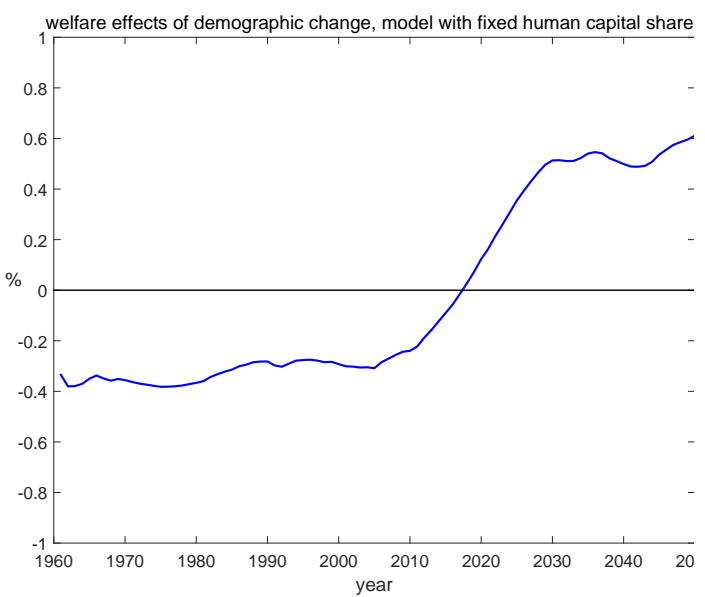

(b) Flexible Human Capital Adiustments

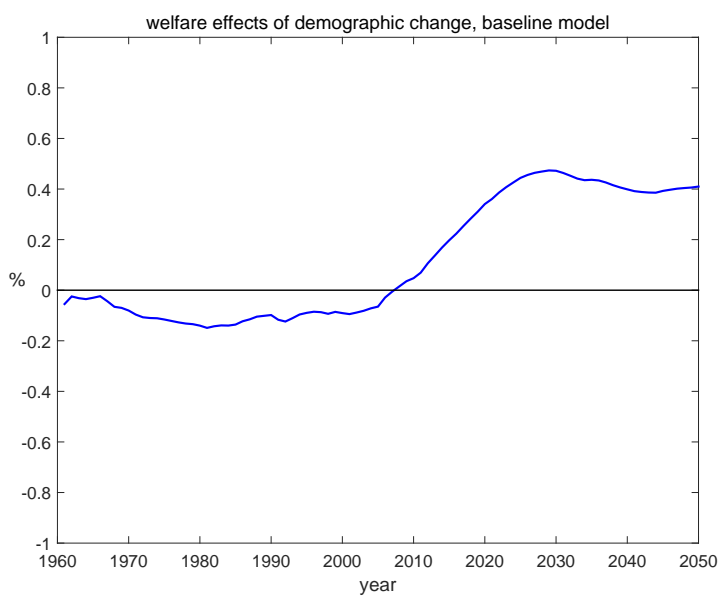

Notes: Welfare evaluation in the model with fixed human capital shares (Panel (a)) and with flexible human capital adjustment (Panel (b)) in the main period of projection. Welfare effects of the generation born in the indicated year measured as consumption equivalent variation. Birth of a generation occurs when individuals turn 20. Negative values indicate welfare losses from demographic change.

It is important to emphasize that these welfare analyses were conducted in a model without social insurance systems. If future contribution rates to pension and health insurance rise tremendously such that increases in gross human capital returns are effectively taxed away and net returns decrease rather than increase, then we conjecture that young and future generations will rather lose from demographic change. ${ }^{21}$ Our current research focuses on extending our model to include (reforms to) social security systems.

\footnotetext{
${ }^{21}$ This is suggested by the analysis in Ludwig, Schelkle, and Vogel (2012).
} 


\section{Conclusion}

This paper develops a quantitative overlapping generations model to evaluate the effects of demographic change for secular stagnation of the US economy in the next decades. We show that cumulative output losses from reductions of raw labor may stand at minus $6 \%$ in 2035, relative to a constant growth path. Endogenous human capital adjustments may strongly reduce these losses to about minus $2 \%$. This relative reduction in long-run output will be accompanied by falling asset returns. Risky returns are projected to decrease by 0.7 , respectively 0.16 , percentage points and risk-free returns by 1.0 , respectively 0.24 , percentage points without, respectively with, human capital adjustments; hence, the equity premium is projected to increase. These developments lead to profound welfare losses for old and asset rich households when human capital adjustments are restricted. These losses can be dampened substantially when human capital adjusts fully flexibly. On the contrary, future generations benefit from being born into an economy with shortage of labor. Furthermore, our predictions, and in particular our predictions of the risk-free rate, are crucial for providing central banks with the necessary information for fine tuning monetary policy instruments in light of the demographic transition.

The differences across human capital scenarios in our model are large. While we do not model frictions to human capital adjustments, these differences lead us to conclude that human capital policies will play a crucial role in aging societies. Extending our framework by an explicit model of such frictions (e.g., borrowing and time constraints to human capital formation) is a key relevant step for future research. However, such an extension would come at the huge cost of having to give up the computational tractability of our current framework.

The current version of the paper does not address how (reforms to) social security systems affect the analysis. The main emphasis of our current research is on extending our model along these lines. 


\section{A Theoretical Appendix}

\section{A.1 Solution of the Household Problem}

Proof of Proposition 1. We guess that $v=m^{l} \cdot \tilde{x}$ where $l$ is some parameter to be determined below and $m$ is the marginal propensity to consume out of $\tilde{x}$ and show below that this is indeed true. From the guess it follows that

$$
\begin{aligned}
v & =\max _{\tilde{c}, \tilde{x}^{\prime}, \widehat{\alpha}^{s^{\prime}}, \widehat{\alpha}^{h^{\prime}}}\left\{\tilde{c}^{\frac{1-\theta}{\gamma}}+\widehat{\beta} \cdot\left(\mathbb{E}\left[\left(m^{\prime l} \cdot \tilde{x}^{\prime}\right)^{1-\theta}\right]\right)^{\frac{1}{\gamma}}\right\}^{\frac{\gamma}{1-\theta}} \text { s.t. } \tilde{x}^{\prime}=\frac{1}{1+g} \cdot(\tilde{x}-\tilde{c}) \cdot\left(1+\widehat{r}^{\prime}\right) \\
& =\max _{\tilde{c}, \widehat{\alpha}^{s^{\prime}}, \widehat{\alpha}^{h \prime}}\left\{\tilde{c}^{\frac{1-\theta}{\gamma}}+\left(\frac{1}{1+g} \cdot(\tilde{x}-\tilde{c})\right)^{\frac{1-\theta}{\gamma}} \cdot \widehat{\beta} \cdot\left(\mathbb{E}\left[\left(m^{\prime l} \cdot\left(1+\widehat{r}^{\prime}\right)\right)^{1-\theta}\right]\right)^{\frac{1}{\gamma}}\right\}^{\frac{\gamma}{1-\theta}}
\end{aligned}
$$

Next, we compute the first-order conditions (FOCs) with respect to $\tilde{c}, \widehat{\alpha}^{s \prime}, \widehat{\alpha}^{h \prime}$ :

- FOC with respect to consumption:

$$
\begin{aligned}
& 0=\frac{\gamma}{1-\theta} \cdot\left\{\tilde{c}^{\frac{1-\theta}{\gamma}}+\left(\frac{1}{1+g} \cdot(\tilde{x}-\tilde{c})\right)^{\frac{1-\theta}{\gamma}} \cdot \widehat{\beta} \cdot\left(\mathbb{E}\left[\left(m^{\prime l} \cdot\left(1+\widehat{r}^{\prime}\right)\right)^{1-\theta}\right]\right)^{\frac{1}{\gamma}}\right\}^{\frac{\gamma}{1-\theta}-1} \\
& \cdot\left\{\frac{1-\theta}{\gamma} \cdot \tilde{c}^{\frac{1-\theta-\gamma}{\gamma}}-\frac{1-\theta}{\gamma \cdot(1+g)} \cdot\left(\frac{1}{1+g} \cdot(\tilde{x}-\tilde{c})\right)^{\frac{1-\theta-\gamma}{\gamma}} \cdot \widehat{\beta} \cdot\left(\mathbb{E}\left[\left(m^{\prime l} \cdot\left(1+\widehat{r}^{\prime}\right)\right)^{1-\theta}\right]\right)^{\frac{1}{\gamma}}\right\} \\
& \tilde{c}=(\tilde{x}-\tilde{c}) \cdot\left(\frac{1}{1+g}\right)^{\frac{1-\theta}{1-\theta-\gamma}} \cdot \widehat{\beta} \frac{\gamma}{1-\theta-\gamma} \cdot\left(\mathbb{E}\left[\left(m^{\prime l} \cdot\left(1+\widehat{r}^{\prime}\right)\right)^{1-\theta}\right]\right)^{\frac{1}{1-\theta-\gamma}} \\
& \text { Defining } n:=\widehat{\beta}^{\frac{\gamma}{1-\theta-\gamma}} \cdot\left(\mathbb{E}\left[\left(m^{\prime l} \cdot\left(1+\widehat{r}^{\prime}\right)\right)^{1-\theta}\right]\right)^{\frac{1}{1-\theta-\gamma}}, o:=\left(\frac{1}{1+g}\right)^{\frac{1-\theta}{1-\theta-\gamma}} \text {, and } m:= \\
& \frac{o \cdot n}{1+o \cdot n} \text {, we get } \\
& \tilde{c}=m \cdot \tilde{x} .
\end{aligned}
$$

- FOC with respect to stock portfolio share:

$$
\begin{aligned}
0= & \frac{\gamma}{1-\theta} \cdot\left\{\tilde{c}^{\frac{1-\theta}{\gamma}}+\left(\frac{1}{1+g} \cdot(\tilde{x}-\tilde{c})\right)^{\frac{1-\theta}{\gamma}} \cdot \widehat{\beta} \cdot\left(\mathbb{E}\left[\left(m^{\prime l} \cdot\left(1+\widehat{r}^{\prime}\right)\right)^{1-\theta}\right]\right)^{\frac{1}{\gamma}}\right\}^{\frac{\gamma}{1-\theta}-1} \\
& \cdot\left(\frac{1}{1+g} \cdot(\tilde{x}-\tilde{c})\right)^{\frac{1-\theta}{\gamma}} \cdot \widehat{\beta} \cdot \frac{1}{\gamma} \cdot\left(\mathbb{E}\left[\left(m^{\prime l} \cdot\left(1+\widehat{r}^{\prime}\right)\right)^{1-\theta}\right]\right)^{\frac{1}{\gamma}-1} \\
& \cdot \mathbb{E}\left[m^{\prime l \cdot(1-\theta)} \cdot(1-\theta) \cdot\left(1+\widehat{r}^{\prime}\right)^{-\theta} \cdot\left(r^{s \prime}-r^{f \prime}\right)\right] \\
0= & \mathbb{E}\left[m^{\prime l \cdot(1-\theta)} \cdot\left(1+\widehat{r}^{\prime}\right)^{-\theta} \cdot\left(r^{s \prime}-r^{f \prime}\right)\right]
\end{aligned}
$$


- FOC with respect to human capital portfolio share:

$$
\begin{aligned}
0= & \frac{\gamma}{1-\theta} \cdot\left\{\tilde{c}^{\frac{1-\theta}{\gamma}}+\left(\frac{1}{1+g} \cdot(\tilde{x}-\tilde{c})\right)^{\frac{1-\theta}{\gamma}} \cdot \widehat{\beta} \cdot\left(\mathbb{E}\left[\left(m^{\prime l} \cdot\left(1+\widehat{r}^{\prime}\right)\right)^{1-\theta}\right]\right)^{\frac{1}{\gamma}}\right\}^{\frac{\gamma}{1-\theta}-1} \\
& \cdot\left(\frac{1}{1+g} \cdot(\tilde{x}-\tilde{c})\right)^{\frac{1-\theta}{\gamma}} \cdot \widehat{\beta} \cdot \frac{1}{\gamma} \cdot\left(\mathbb{E}\left[\left(m^{\prime l} \cdot\left(1+\widehat{r}^{\prime}\right)\right)^{1-\theta}\right]\right)^{\frac{1}{\gamma}-1} \\
& \cdot \mathbb{E}\left[m^{\prime l \cdot(1-\theta)} \cdot(1-\theta) \cdot\left(1+\widehat{r}^{\prime}\right)^{-\theta} \cdot\left(\widehat{r}^{h \prime}-r^{f \prime}\right)\right] \\
0= & \mathbb{E}\left[m^{\prime l \cdot(1-\theta)} \cdot\left(1+\widehat{r}^{\prime}\right)^{-\theta} \cdot\left(\widehat{r}^{h \prime}-r^{f \prime}\right)\right]
\end{aligned}
$$

What is left is to show that indeed $v=m^{l} \cdot \tilde{x}$. Using $\tilde{c}=m \cdot \tilde{x}, n=\widehat{\beta}^{\frac{\gamma}{1-\theta-\gamma}} \cdot\left(\mathbb{E}\left[\left(m^{l l}\right.\right.\right.$. $\left.\left.\left.\left(1+\widehat{r}^{\prime}\right)\right)^{1-\theta}\right]\right)^{\frac{1}{1-\theta-\gamma}}, m=\frac{o \cdot n}{1+o \cdot n}$, and $o=\left(\frac{1}{1+g}\right)^{\frac{1-\theta}{1-\theta-\gamma}}$ in $u$ we get:

$$
\begin{aligned}
v & =\left\{(m \cdot \tilde{x})^{\frac{1-\theta}{\gamma}}+\left(\frac{1}{1+g} \cdot(\tilde{x}-m \cdot \tilde{x})\right)^{\frac{1-\theta}{\gamma}} \cdot n^{\frac{1-\theta-\gamma}{\gamma}}\right\}^{\frac{\gamma}{1-\theta}} \\
& =\tilde{x} \cdot\left\{\frac{(o \cdot n)^{\frac{1-\theta-\gamma}{\gamma}}}{(1+o \cdot n)^{\frac{1-\theta-\gamma}{\gamma}}}\right\}^{\frac{\gamma}{1-\theta}}=\tilde{x} \cdot m^{\frac{1-\theta-\gamma}{1-\theta}}
\end{aligned}
$$

Hence, $v=m^{l} \cdot \tilde{x}$ where $l=\frac{1-\theta-\gamma}{1-\theta}$. Plugging this into the FOCs yields:

$$
\begin{aligned}
& \tilde{c}=m \cdot \tilde{x} \\
& 0=\mathbb{E}\left[\left(m^{\prime}\right)^{1-\theta-\gamma} \cdot\left(1+\widehat{r}^{\prime}\right)^{-\theta} \cdot\left(r^{s^{\prime}}-r^{f \prime}\right)\right] \\
& 0=\mathbb{E}\left[\left(m^{\prime}\right)^{1-\theta-\gamma} \cdot\left(1+\widehat{r}^{\prime}\right)^{-\theta} \cdot\left(\widehat{r}^{h \prime}-r^{f \prime}\right)\right]
\end{aligned}
$$

Defining $\wp:=\mathbb{E}\left[\left(m^{\frac{1-\theta-\gamma}{1-\theta}} \cdot\left(1+\widehat{r}^{\prime}\right)\right)^{1-\theta}\right]$, the marginal propensity to consume equals:

$$
\begin{aligned}
m & =\frac{o \cdot n}{1+o \cdot n}=\frac{\left(\frac{1}{1+g}\right)^{\frac{1-\theta}{1-\theta-\gamma}} \cdot \widehat{\beta} \frac{\gamma}{1-\theta-\gamma} \cdot \wp^{\frac{1}{1-\theta-\gamma}}}{1+\left(\frac{1}{1+g}\right)^{\frac{1-\theta}{1-\theta-\gamma}} \cdot \widehat{\beta} \frac{\gamma}{1-\theta-\gamma} \cdot \wp^{\frac{1}{1-\theta-\gamma}}} \\
& =\frac{\left(\beta \cdot \varsigma^{\frac{1}{\gamma}}\right)^{\frac{\gamma}{1-\theta-\gamma}} \cdot \wp^{\frac{1}{1-\theta-\gamma}}}{1+\left(\beta \cdot \varsigma^{\frac{1}{\gamma}}\right)^{\frac{\gamma}{1-\theta-\gamma}} \cdot \wp^{\frac{1}{1-\theta-\gamma}}}=\frac{\left(\beta^{\gamma} \cdot \varsigma \cdot \wp\right)^{\frac{1}{1-\theta-\gamma}}}{1+\left(\beta^{\gamma} \cdot \varsigma \cdot \wp\right)^{\frac{1}{1-\theta-\gamma}}}
\end{aligned}
$$




\section{A.2 Derivation of the Aggregate Resource Constraint}

Deriving the aggregate resource constraint, first we take the population weighted sums of the (de-trended) individual budget constraints and the individual human capital accumulation constraints in period $t$ (cf. equations (9) and (8)) and add them up. Note that it is understood that we sum over all individuals of each age bin characterized by the idiosyncratic mean zero-shock $\eta$ without making this explicit. We then get

$$
\begin{aligned}
(1+g) & \cdot \sum_{j=0}^{J} N_{t, j} \cdot \tilde{k}_{t+1, j+1}+\sum_{j=0}^{J} N_{t, j} \cdot h_{t+1, j+1} \\
= & \sum_{j=0}^{J} N_{t, j} \cdot \tilde{k}_{t, j} \cdot\left(1+r_{t}^{f}+\alpha_{t, j}^{s} \cdot\left(r_{t}^{s}-r_{t}^{f}\right)\right)+\sum_{j=0}^{J} N_{t, j} \cdot h_{t, j} \cdot \tilde{r}_{t}^{H} \\
& -\sum_{j=0}^{J} N_{t, j} \cdot \tilde{c}_{t, j}+\sum_{j=0}^{J} N_{t, j} \cdot h_{t, j} \cdot\left(1-\delta_{j}^{h}\right) \\
\Leftrightarrow \quad & \tilde{K}_{t+1}+H_{t+1} \\
= & \tilde{K}_{t}+\tilde{K}_{t} \cdot r_{t}^{K}+H_{t}+H_{t} \cdot \tilde{r}_{t}^{H}-\tilde{G}_{t}-\tilde{C}_{t} \\
& -\sum_{j=0}^{J} N_{t, j} \cdot\left(1-\varsigma_{t, j}\right) \cdot h_{t+1, j+1}+N_{t+1,0} \cdot h_{t+1,0}-\sum_{j=0}^{J} N_{t, j} \cdot h_{t, j} \cdot \delta_{j}^{h}
\end{aligned}
$$

or, finally,

$$
\tilde{Y}_{t}=\tilde{C}_{t}+\tilde{G}_{t}+\tilde{I}_{t}^{K}+I_{t}^{h}
$$

where we used equilibrium conditions summarized in 2.8 as well as $K_{t+1}=K_{t} \cdot(1-$ $\left.\delta_{t}^{K}\right)+I_{t}^{K}$ and $I_{t+1}^{H}=H_{t}+I_{t}^{H}$. Note that $I_{t}^{h}$ is the aggregate of gross human capital investments defined as: $I_{t}^{h}:=I_{t}^{H}-N_{t+1,0} \cdot h_{t+1,0}+\sum_{j=0}^{J} N_{t, j} \cdot\left(1-\varsigma_{t, j}\right) \cdot h_{t+1, j+1}+$ $\sum_{j=0}^{J} N_{t, j} \cdot h_{t, j} \cdot \delta_{j}^{h}$.

\section{B Computational Appendix}

Numerical computations are implemented in Fortran 90 using routines which are partly based on Press, Teukolsky, Vetterling, and Flannery (1996). If not otherwise 
stated the convergence criterion of a root finding algorithm is set to $10^{-6}$ and the weight on resulting variables in the updating step of a Gauss-Seidel algorithm (cf., e.g., Ludwig 2007) is set to $10 \%$.

\section{B.1 Numerical Solution}

We solve an approximate rational expectations equilibrium by adapting the computational method developed in Krusell and Smith $(1997,1998)$ to the case of transitional dynamics with time-varying aggregate laws of motion due to a time-varying demographic distribution, $N$. Therefore, we follow the approach in Geppert and Ludwig (2015). 


\section{References}

Attanasio, O., S. Kitao, and G. L. Violante (2007). Global Demographic Trends and Social Security Reform. Journal of Monetary Economics 54(1), 144-198.

Auerbach, A. J. and L. J. Kotlikoff (1987). Dynamic Fiscal Policy. Cambridge, MA: Cambridge University Press.

Bakshi, G. S. and Z. Chen (1994). Baby Boom, Population Aging and Capital Markets. Journal of Business 67, 165-202.

Bansal, R. and A. Yaron (2004). Risks for the Long Run: A Potential Resolution of Asset Pricing Puzzles. 59(4), 1481-1509.

Barberis, N. (2000). Investing for the Long Run When Returns are Predictable. Journal of Finance 55, 225-264.

Boldrin, M., L. J. Christiano, and J. D. M. Fisher (1995). Asset Pricing Lessons for Modeling Business Cycles. NBER Working Paper Series 5262.

Bommier, A., D. Harenberg, and F. Legrand (2016). Life-Cycle Asset Allocation with Recursive Preferences.

Börsch-Supan, A., A. Ludwig, and M. Sommer (2003). \{Demographie und Kapitalmärkte - Die Auswirkungen der Bevölkerungsalterung auf Aktien-\}, $\{$ Renten- $\}$ und $\{$ Immobilienvermögen $\}$. Köln: DIA, \{Deutsches Institut für Altersvorsorge $\}$.

Börsch-Supan, A., A. Ludwig, and J. Winter (2006). Aging, Pension Reform and Capital Flows: A Multi-Country Simulation Model. Economica 73, 625-658.

Brooks, R. (2004). The Equity Premium and the Baby Boom. Econometric Society 2004 North American Winter Meetings 155, 1-25.

Campbell, J. Y. and L. M. Viceira (2002). Strategic Asset Allocation: Portfolio Choice for Long-Term Investors. Oxford University Press.

Carvalho, C., A. Ferrero, and F. Nechio (2016). Demographics and Real Interest Rates: Inspecting the Mechanism.

Constantinides, G. M. and D. Duffie (1996). Asset Pricing with Heterogeneous Consumers. Journal of Political Economy 104, 219-240.

Córdoba, J. C. and M. Ripoll (2016). Risk Aversion and the Value of Life. 
Croce, M. (2014). Long-run productivity risk: A new hope for production-based asset pricing? Journal of Monetary Economics 66, 13-31.

Davila, J., J. H. Hong, P. Krusell, and J.-V. Rios-Rull (2012). Constrainded Efficiency in the Neoclassical Growth Model with Uninsurable Idiosyncratic Shocks. Econometrica 80(6)(80(6)), 2431-2467.

Diamond, P. A. (1965). National Debt in a Neoclassical Growth Model. American Economic Review 55, 1126-1150.

Eggertsson, G. B. and N. R. Mehrotra (2014). A Model of Secular Stagnation.

Eggertsson, G. B., N. R. Mehrotra, and L. H. Summers (2016). Secular Stagnation in the Open Economy.

Epstein, L. and S. Zin (1991). Substitution, Risk Aversion, and the Temporal Behavior of Consumption and Asset Returns: A Theoretical Framework. Journal of Political Economy 99, 263-286.

Epstein, L. G. and S. Zin (1989). Substitution, Risk Aversion, and the Temporal Behavior of Consumption and Asset Returns: A Theoretical Framework. Econometrica 57(4), 937-969.

Fernández-Villaverde, J. and D. Krüger (2006). Consumption over the Life Cycle: Facts from Consumer Expenditure Survey Data. Review of Economics and Statistics 89(3), 552-565.

Geanakoplos, J., M. Magill, and M. Quinzii (2004). Demography and the LongRun Predictability of the Stock Market. Brookings Papers on Economic Activity 1, 241-307.

Geppert, C. and A. Ludwig (2015). Computing Transitional Dynamics in Heterogenous Agent Models with Aggregate Risk by Parameterized Laws of Motion. Mimeo.

Glover, A., J. Heathcote, D. Krueger, and J. V. Rios-Rull (2014). Intergenerational Redistribution in the Great Recession.

Gomes, F. and A. Michaelides (2008). Asset Pricing with Limited Risk Sharing and Heterogeneous Agents. The Review of Financial Studies 21(1), 415-449.

Guvenen, F., S. Ozkan, and J. Song (2014). The Nature of Countercyclical Income Risk. Journal of Political Economy 122(3), 1-59. 
Hansen, A. (1938). Full Recovery or Stagnation. W. W. Norton.

Harenberg, D. and A. Ludwig (2015). Idiosyncratic Risk, Aggregate Risk, and the Welfare Effects of Social Security. Mimeo.

Huggett, M., G. Ventura, and A. Yaron (2011). Sources of Lifetime Inequality. American Economic Review 101, 2923-2954.

Hugonnier, J., F. Pelgrin, and P. St-Amour (2013). Health and (Other) Asset Holdings. Review of Economic Studies 80, 663-710.

Human Mortality Database (2008). No title. University of California, Berkeley (USA), and Max Planck Institutefor Demographic Research (Germany) [accessed at http://www.mortality.org/ on April 12, 2010].

Judd, K. L. (2002). The Parametric Path Method: An Alternative to \{FairTaylor $\}$ and $\{$ L-B-J\} for Solving Perfect Foresight Models. Journal of Economic Dynamics and Control 26, 1557-1583.

Krebs, T. (2003). Human Capital Risk and Economic Growth. Quarterly Journal of Economics 118, 709-745.

Krebs, T. and B. Wilson (2004). Asset Returns in an Endogenous Growth Model with Incomplete Markets. Journal of Economic Dynamics and Control, 817839.

Krüger, D. and F. Kübler (2006). Pareto Improving Social Security Reform When Financial Markets are Incomplete!? American Economic Review 96(3), 737755.

Krüger, D. and A. Ludwig (2007). On the Consequences of Demographic Change for Rates of Return to Capital and the Distribution of Wealth and Welfare. Journal of Monetary Economics 54(1), 49-87.

Krusell, P. and A. A. Smith (1997). Income and Wealth Heterogeneity, Portfolio Choice, and Equilibrium Asset Returns. Macroeconomic Dynamics 1, 387-422.

Krusell, P. and A. A. Smith (1998). Income and Wealth Heterogeneity and the Macroeconomy. Journal of Political Economy 106, 867-896.

Kuhle, W. (2008). Demography and Equity Premium. 
Ludwig, A. (2007). The Gauss-Seidel-Quasi-Newton Method: A Hybrid Algorithm for Solving Dynamic Economic Models. Journal of Economic Dynamics and Control 31(5), 1610-1632.

Ludwig, A., T. Schelkle, and E. Vogel (2012). Demographic Change, Human Capital and Welfare.

Mehra, R. and E. Prescott (1985). The Equity Premium: A Puzzle. Journal of Monetary Economics 15, 145-161.

Merton, R. C. (1969). Litetime Portfoliio Selection under Uncertainty: The Continuous-Time Case. The Review of Economics and Statistics 51(3), 247257.

Piazzesi, M., M. Schneider, and S. Tuzel (2007). Housing, Consumption, and Asset Pricing. Journal of Financial Economics 83(3), 531-569.

Press, W. H., S. A. Teukolsky, W. T. Vetterling, and B. P. Flannery (1996). Numerical Recipes in Fortran 90. New York: Cambridge University Press.

Rajan, R. G. and L. Zingales (1995). What Do We Know about Capital Structure? Some Evidence from International Data. The Journal of Finance 50(5), 14211460 .

Samuelson, P. A. (1969). Lifetime Portfolio Selection by Dynamic Stochastic Programming. Review of Economics and Statistics 51(3)(Vol. 51, No. 3.), 239-246.

Shiller, R. (2015). U.S. Stock Price Data, Annual, with consumption, both short and long rates, and present value calculations. [accessed at http://www.econ.yale.edu/ shiller/data.htm on May 26, 2015].

Storesletten, K., C. Telmer, and A. Yaron (2004). Cyclical Dynamics in Idiosyncratic Labor Market Risk. Journal of Political Economy 112, 695-717.

Storesletten, K., C. Telmer, and A. Yaron (2007). Asset Pricing with Idiosyncratic Risk and Overlapping Generations. Review of Economic Dynamics 10(4), 519548.

Summers, L. H. (2013). IMF Fourteenth Annual Research Conference in Honor of Stanley Fischer.

Summers, L. H. (2014). U.S. Economic Prospects: Secular Stagnation, Hysteresis, and the Zero Lower Bound. Business Economics 49(2), 65-73. 
Taylor, J. B. (1993). Discretion versus Policy Rules in Practice. CarnegieRochester Conference Series on Public Policy 39, 195-214.

Teulings, C. and R. Baldwin (2014). Secular Stagnation: Facts, Causes and Cures. VoxEU.org.

United Nations (2007). World Population Prospects: The 2006 Revision. New York: United Nations.

Weil, P. (1989). The Equity Premium Puzzle and the Risk-Free Rate Puzzle. Journal of Monetary Economics 24, 401-421.

Wicksell, K. (1898). Interest and Prices. New York: Sentry Press. 


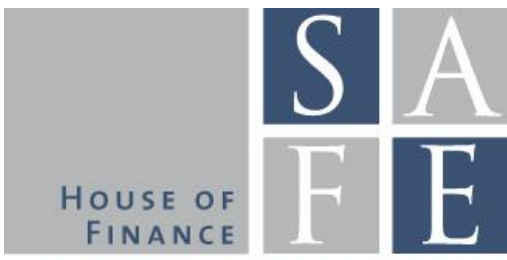

WORKING PAPER SERIES

\section{Recent Issues}

No. 144 Mario Bellia, Loriana Pelizzon, Marti G. Subrahmanyam, Jun Uno, Darya Yuferova

No. 143 Peter Gomber, Satchit Sagade, Erik Theissen, Moritz Christian Weber, Christian Westheide

No. 142 Nathanael Vellekoop

No.141 Brigitte Haar

No. 140 Reint Gropp, Rasa Karapandza, Julian Opferkuch

No. 139 Holger Kraft, Claus Munk, Farina Weiss

No. 138

Mohammed Aldegwy, Matthias Thiemann

No. 137 Elia Berdin, Cosimo Pancaro, Christoffer Kok

No. 136

Matthias Thiemann, Mohammed Aldegwy, Edin Ibrocevic

No. 135

Douglas Cumming, Jochen Werth, Yelin Zhang

No.134 Markus Kröll, Devesh Rustagi

No. 133
Markus Behn, Rainer Haselmann, Thomas Kick, Vikrant Vig
Low-Latency Trading and Price Discovery: Evidence from the Tokyo Stock Exchange in the Pre-Opening and Opening Periods

Spoilt for Choice: Order Routing Decisions in Fragmented Equity Markets

The Impact of Long-Run Macroeconomic Experiences on Personality

Freedom of Contract and Financial Stability through the lens of the Legal Theory of Finance

The Forward-Looking Disclosures of Corporate Managers: Theory and Evidence

Predictors and Portfolios Over the Life Cycle

How Economics Got it Wrong: Formalism, Equilibrium Modelling and PseudoOptimization in Banking Regulatory Studies

A Stochastic Forward-Looking Model to Assess the Profitability and Solvency of European Insurers

Understanding the Shift from Micro to MacroPrudential Thinking: A Discursive Network Analysis

Governance in Entrepreneurial Ecosystems: Venture Capitalists vs. Technology Parks

Got Milk? Motivation for Honesty and Cheating in Informal Markets: Evidence from India

The Political Economy of Bank Bailouts 